\title{
Perovskite/Organic Hybrid White Electroluminescent Devices with Stable Spectrum and Extended Operating Lifetime
}

Denghui Liu, Xinyan Liu, Yiyang Gan, Zhe Liu, Guanwei Sun, Chenyang Shen, Xiaomei Peng, Weidong Qiu, Deli Li, Zhisheng Zhou, Zhenchao Li, Hin-Lap Yip and Shi-Jian Su*

State Key Laboratory of Luminescent Materials and Devices and Institute of Polymer Optoelectronic Materials and Devices, South China University of Technology, Wushan Road 381, Guangzhou 510640, China

E-mail: $\underline{\text { mssjsu@sscut.edu.cn }}$ 


\section{Note S1:}

\section{Preparation and characterization of $\mathrm{Zn}-\mathrm{Pb}$ quasi-2D pure-red perovskite films:}

To realize high-performance perovskite/organic hybrid white LEDs, high-quality perovskite film with low defect density and compact morphology is a prerequisite. Compared with the bulk three-dimensional (3D) perovskite, the multi-quantum well (MQW) structure in quasi-2D perovskite exhibits increased exciton binding energy and suppressed trap density due to its dielectric confinement effect. ${ }^{1-3}$ Here, the optimized (PEA) $)_{2}\left(\mathrm{Cs}_{0.3} \mathrm{MA}_{0.7}\right)_{2}\left(\mathrm{~Pb}_{0.7} \mathrm{Zn}_{0.3}\right)_{3} \mathrm{I}_{10}$ : TAPC (at a mass ratio of 100: 2 in precursor) perovskite film is used, also called as $\mathrm{Zn}-\mathrm{Pb}$ quasi-2D perovskite. $\mathrm{PEAI}$ is used to develop quasi-2D perovskite structure. Singular iodide was employed to fabricate red emitting perovskite. Owing to the avoidance of mixed halide ions redistribution under applied electric field, the obtained monochromatic devices possess stable EL spectra under various driving voltages, ${ }^{4,} 5$ which endows the possibility of generating stable white emission. TAPC was doped into the precursor solution to further increase the hole transport property of the perovskite film. The valance band of the perovskite film is derived from the result of atmospheric ultraviolet photoelectron spectroscopy (Figure S1b). The preparation of the perovskite film can refer to Experimental Section.

X-ray diffraction (XRD) measurement was conducted to determine the perovskite structure (Figure S2). Two main characteristic diffraction peaks located at around $14^{\circ}$ and $29^{\circ}$ can be observed in the film, corresponding to (100) and (200) planes of the cubic perovskite structure, respectively.

The formed perovskite film has a good film formability, which can be confirmed by the measurements of top-view atomic force microscope (AFM) and scanning electronic microscope (SEM). As shown in Figure S3a, compact and continuous surface morphology can be observed, and the root-mean-square roughness is as low as $1.38 \mathrm{~nm}$. Figure S3b shows that the perovskite film exhibits uniform crystal size and high film coverage. 
Pure-red $\mathrm{Zn}-\mathrm{Pb}$ quasi-2D perovskite film with smooth and continuous surface morphology was selected based on the following considerations: (i) Aside from the increased exciton binding energy and suppressed trap density in the formed quasi-2D perovskite structure with multi-quantum well (MQW), the fast energy transfer (ET) from large to small band gap MQWs leads to efficient radiative decay and improved PLQY, and thus less injected charges are captured by the perovskite crystal surface defects; (ii) Although the larger exciton binding energy in quasi-2D perovskite facilitates to confine the injected charges to form excitons, however, the passed electrons from cathode are controlled by the embedded p-HTL (TAPC), and thus a part of excess holes in the perovskite layer will be allowed to be transported to the nearly barrier-free TAPC layer, then encounter with the extra electrons accumulated at the interlayer to form excitons for enhanced blue emission; (iii) $\mathrm{Zn}$ is a low-cost and non-toxic element which has abundant reserves in nature, and it is incorporated into this perovskite system for reducing the toxicity of $\mathrm{Pb}$. Pure-red perovskite LED was also fabricated in an architecture of ITO/ m-PEDOT: PSS $(30 \mathrm{~nm}) /$ perovskite $(50 \mathrm{~nm}) / \mathrm{TPBI}(30 \mathrm{~nm}) / \mathrm{CsF}(1.2 \mathrm{~nm}) / \mathrm{Al}(120 \mathrm{~nm})$ (device R1) for comparison. As shown in Figure S4a and Figure S4d, the normalized EL spectra peak at $654 \mathrm{~nm}$ with stable spectrum under various applied bias. Corresponding CIE coordinates is $(0.699$, 0.301 ), approaching the standard pure-red emission (Rec. 2100 specification). ${ }^{6}$ The detailed performance parameters are summarized in Table S2.

For the blue component, a sky-blue emitting organic phosphorescent complex (FIrpic) was adopted. UV-vis absorption and photoluminescence (PL) spectra of FIrpic and perovskite are shown in Figure S5a. For the perovskite film, multiple excitonic absorption peaks are emerging at 566, 613 and $645 \mathrm{~nm}$, corresponding to $\mathrm{n}=2,3$ and 4 quasi-2D perovskite structure, respectively. Since the pure-red emitting perovskite film with mixed layered quasi-2D phases exhibits broader full width at half maximum (FWHM), the spectrum coverage will be broadened as compensation for sky-blue light emission. Additionally, according to the CIE 1931 chromaticity coordinates of 
FIrpic and perovskite in their EL devices (Figure S5b), white emission can be expected, because the line (black) connecting their CIE coordinates pass through the white emission region.

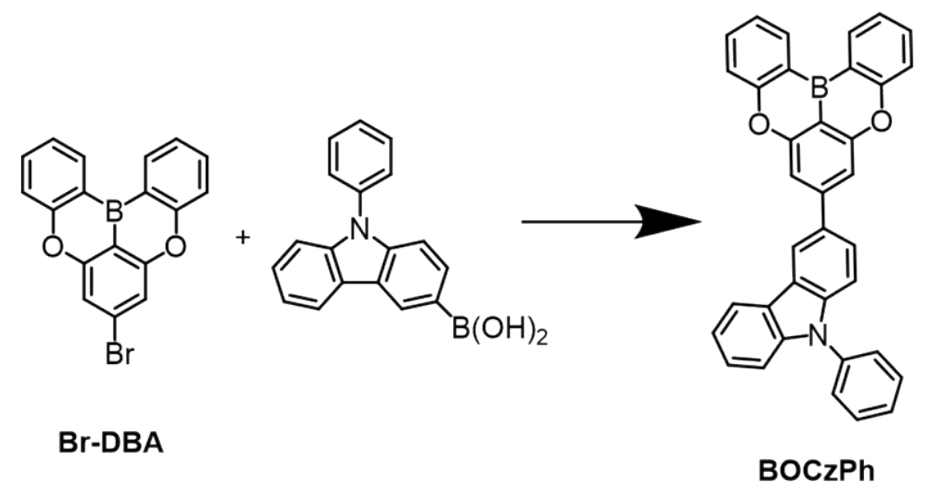

Scheme S1. Synthetic procedure of the n-type electron transport material $\mathrm{BOCz} \mathrm{Ph}$.

BOCzPh was synthesized by a simple Suzuki reaction from Br-DBA. The synthetic procedure of Br-DBA followed the reported literatures. ${ }^{7,} 8$ Under nitrogen ambience, Br-DBA (3.49 g, $10 \mathrm{mmol})$, (9-phenyl-9H-carbazol-3-yl) boronic acid (2.87 g, 10 $\mathrm{mmol}), \mathrm{K}_{2} \mathrm{CO}_{3}(5.60 \mathrm{~g}), \mathrm{Pd}\left(\mathrm{PPh}_{3}\right)_{4}(0.15 \mathrm{~g})$, deionized water $(15 \mathrm{~mL})$, THF $(60 \mathrm{~mL})$ and toluene $(90 \mathrm{~mL})$ were added into a $250 \mathrm{~mL}$ three-necked bottle. The reaction mixture was stirred at $85{ }^{\circ} \mathrm{C}$ for $10 \mathrm{~h}$. After termination of the reaction, the mixture was extracted with dichloromethane (DCM). The solvent was removed by vacuum distillation. The residue was precipitated in methanol, and the precipitation was further purified by column chromatography to afford a white powder $(4.10 \mathrm{~g}$, yield 80.1\%). MS (EI): m/z [M]+: calculated: 511.39, found: 511.45 .

BOCzPh: ${ }^{1} \mathrm{H}$ NMR (500 MHz, chloroform-d) $\delta$ (ppm) 8.67 (dd, $J=7.7,1.7 \mathrm{~Hz}, 2 \mathrm{H}$ ), $8.53(\mathrm{~d}, J=1.7 \mathrm{~Hz}, 1 \mathrm{H}), 8.22(\mathrm{dt}, J=7.8,1.0 \mathrm{~Hz}, 1 \mathrm{H}), 7.81(\mathrm{dd}, J=8.5,1.9 \mathrm{~Hz}, 1 \mathrm{H})$, 7.70 (ddd, $J=8.5,7.0,1.7 \mathrm{~Hz}, 2 \mathrm{H}), 7.66-7.53(\mathrm{~m}, 8 \mathrm{H}), 7.50$ (dd, $J=7.9,6.2 \mathrm{~Hz}$, 2H), $7.45-7.41(\mathrm{~m}, 2 \mathrm{H}), 7.41-7.30(\mathrm{~m}, 3 \mathrm{H})$, as shown in Figure S24.

${ }^{13} \mathrm{C}$ NMR (126 MHz, chloroform- $d$ ) $\delta$ (ppm) 160.69, 157.74, 141.44, 140.99, 137.49, $134.53,133.46,132.40,129.96,127.64,127.08,126.31,125.71,123.99,123.44$, $122.73,120.36(\mathrm{~d}, J=14.6 \mathrm{~Hz}), 119.43,118.43,113.20,110.09(\mathrm{~d}, J=18.8 \mathrm{~Hz})$, 107.11, as shown in Figure S25. 


\section{Note S2:}

\section{The formation of interfacial exciplex:}

As shown in Figure S6, the maximum emission peaks of TAPC and BOCzPh in neat film are located at $376 \mathrm{~nm}$ and $443 \mathrm{~nm}$, respectively. Then, blue light emission device B1 was fabricated with a structure of ITO/ m-PEDOT: PSS (30 nm)/ TAPC (5 nm)/ BOCzPh $(20 \mathrm{~nm}) / \mathrm{TPBI}(30 \mathrm{~nm}) / \mathrm{CsF}(1.2 \mathrm{~nm}) / \mathrm{Al}(120 \mathrm{~nm})$ for comparison. As shown in Figure S7a, a new emission peak of $480 \mathrm{~nm}$ emerged in the EL spectrum of the device B1, which is red-shifted compared with the PL spectra of TAPC and $\mathrm{BOCz} \mathrm{Ph}$, indicating the formation of interfacial exciplex. The detailed performance parameters are summarized in Table S2.

\section{Note S3:}

\section{Sensitization of the organic phosphorescent interlayer by the formed interfacial} exciplex:

The phosphorescent emitter FIrpic incorporates a heavy atom (iridium) into the emitting chromophore to enhance spin-orbit coupling and hence facilitate intersystem crossing (ISC) from $\mathrm{S}_{1}$ to $\mathrm{T}_{1}$ and likewise $\mathrm{T}_{1}$ to $\mathrm{S}_{0}$, giving transition allowed phosphorescence, thus blue light emission stems from the radiative transition process of triplet excitons. For the exciplex forming hosts, the charge recombination is dominated by Langevin recombination rather than trap-assisted recombination, especially for the current organic p-i-n heterojunction with an ultra-thin phosphorescent interlayer. Considering the higher $S_{1}$ and $T_{1}$ energy levels of the exciplex than that of the phosphorescent emitter FIrpic, Föster and Dexter energy transfer from the exciplex to the dopant can be allowed to give singlet and triplet excitons of the phosphorescent emitter. Then, the effective intersystem crossing from $\mathrm{S}_{1}$ to $\mathrm{T}_{1}$ of the phosphorescent emitter give transition allowed $T_{1}$ and thus radiative transition for blue light emission. ${ }^{9}, 10$ Additionally, formation of exciplex between two molecules would exhibit red-shifted emission in comparison to the emission spectrum of each component. In the current work, exciplex can be formed between TAPC and 
BOCzPh. In spite of the red-shifted emission, it still possesses higher singlet and triplet energies than the phosphorescent emitter FIrpic, guaranteeing efficient energy transfer from the exciplex to the phosphorescent emitter and thus high exciton utilization efficiency. Different from the most exciplex systems with a binary mixing donor and acceptor, the current exciplex was also formed by interlayer charge transfer between the p-HTL (TAPC) and n-ETL (BOCzPh). It is unique since the p-HTL also acts as the electron transport modulation layer to regulate the overall carrier distribution within the device, and the modulation of exciton recombination region is essential for the co-emission from the perovskite layer and the organic light-emitting unit. Blue light emission device B2 was fabricated with an architecture of ITO/ mPEDOT: PSS (30 nm)/ TAPC (5 nm)/ FIrpic (1 nm)/ BOCzPh (20 nm)/ TPBI (30 $\mathrm{nm}) / \mathrm{CsF}(1.2 \mathrm{~nm}) / \mathrm{Al}(120 \mathrm{~nm})$. Different from device B1, an ultra-thin doping-free organic phosphorescent interlayer was inserted between the p-type TAPC layer and ntype BOCzPh layer. As shown in Figure S8, only the emission from FIrpic can be observed in the EL spectrum of device B2, indicating the formed exciplex can be served as a higher triplet energy host to sensitize the FIrpic interlayer. The detailed performance parameters are summarized in Table S2. As for the n-ETL, 20-nm $\mathrm{BOCzPh}$ layer is the optimized thickness for high-efficiency organic p-i-n heterojunction unit. In addition, device B3 without the n-ETL BOCzPh was also prepared for comparison (device configuration: ITO/ m-PEDOT: PSS (30 nm)/ TAPC $(5 \mathrm{~nm}) /$ FIrpic $(1 \mathrm{~nm}) /$ TPBI $(30 \mathrm{~nm}) / \mathrm{CsF}(1.2 \mathrm{~nm}) / \mathrm{Al}(120 \mathrm{~nm}))$. It is obvious that the device $\mathrm{B} 3$ without using the n-ETL $(\mathrm{BOCz} \mathrm{Ph})$ exhibits worse device performance compared with the device B2 (Figure S9, Table S2). As thus, the utilization of the $\mathrm{BOCzPh}$ layer in the $\mathrm{p}-\mathrm{i}-\mathrm{n}$ heterojunction is necessary for realizing high-performance perovskite/organic hybrid white electroluminescent device.

When $\mathrm{Zn}-\mathrm{Pb}$ quasi-2D perovskite film was used in the presented device configuration, exciton recombination zone can be modulated by introducing the organic p-i-n heterojunction unit, the insertion of TAPC layer may lead to the reduction of effective carriers for recombination within the perovskite layer. However, when carriers are 
injected into the device without using the TAPC layer, electrons from the cathode are effectively transported to the perovskite layer may also lead to holes from anode mainly participate in the recombination within the perovskite layer for red emission. Under this condition, holes are hardly able to be transported to the organic lightemitting unit, exciton recombination zone was still confined in the perovskite layer, white emission from both light-emitting units will not be observed. For example, device W6 without the p-HTL TAPC was fabricated for comparison (device structure: ITO/ m-PEDOT: PSS (30 nm)/ Perovskite (40 nm)/ FIrpic (1 nm)/ BOCzPh (20 nm)/ TPBI $(30 \mathrm{~nm}) / \mathrm{CsF}(1.2 \mathrm{~nm}) / \mathrm{Al}(120 \mathrm{~nm})$. Although the barrier height of this structure was reduced to match the LUMO levels, only the red emission from the perovskite can be observed in its EL spectrum (Figure S10, Table S2), indicating the device without using the TAPC layer will not effectively regulate the exciton recombination zone for realizing the mixing of sky-blue and red colors. Although this process may lead to the reduction of effective carriers for recombination within the perovskite layer, excess holes will be allowed to pass through the TAPC layer, and they further encounter with the extra electrons accumulated at the interlayer to form excitons, then utilized by the organic phosphorescent emitter, and thus the inherent exciton utilization efficiency will not be sacrificed.

\section{Note $\mathbf{5 4}$}

\section{The key limitative factors of the peak brightness and EQE of perovskite/organic hybrid white LEDs mainly include:}

(i) The generated photons are difficult to escape from the inside of the device because of the total internal reflection induced by the large difference in the refractive indices (n) between the perovskite layer and organic layer (perovskite: $\mathrm{n} \sim 2.5$, TAPC: $\mathrm{n}$ 1.6). ${ }^{11}$ (ii) The efficiency of light extraction is determined by the thickness, extinction coefficient (especially for perovskite, the high extinction coefficient may lead to the loss of the generated photons, and thus the possibility of reabsorption of photons by the perovskite layer should be considered), the position of the luminous center, transition dipole moment of each layer materials, which may be the 
fundamental reasons account for this phenomenon.

\section{Note S5}

Preparation and characterization of 40-nm and 30-nm $\mathrm{Zn}-\mathrm{Pb}$ quasi-2D pure-red perovskite films:

The fabrication of $40-\mathrm{nm}$ and $30-\mathrm{nm}$ perovskite films can refer to Experimental Section, and their thickness can be determined by the cross-sectional SEM images (Figure $3 \mathrm{a}$ and Figure S12). The surface morphologies of 40-nm and 30-nm perovskite films spin-coated onto ITO/m-PEDOT: PSS were measured by AFM and SEM. As shown in Figure S13, the corresponding perovskite films are still compact as well as exhibit uniform crystal size and high film coverage, which are crucial for the subsequent vacuum deposition of the TAPC layer. UV-vis absorption (Figure S14a), steady-state PL spectra (Figure S14b), PLQY (Figure S14c) and time-resolved PL decay character (TRPL, Figure S14d) of these perovskite films were measured to evaluate their optical properties. When the thickness of the perovskite films is altered from $50 \mathrm{~nm}$ to $30 \mathrm{~nm}$, the excitonic absorption peaks of these perovskite films are still emerging at 566, 613 and $645 \mathrm{~nm}$, corresponding to $\mathrm{n}=2,3$ and 4 quasi-2D perovskite structures, respectively. The PL peaks and absorption edges of the perovskite films exhibit a small blue-shift, which could result from the change of low-dimensional perovskite components and the reduction of the crystal size. ${ }^{12-14}$ In addition, according to the relative work (ACS Appl. Mater. Interfaces 2021, 13, 55412-55419), $\mathrm{Pb}^{2+}$ (119 pm) was proved to be partially substituted by the smaller ionic radius $\mathrm{Zn}^{2+}$ (74 pm) in this perovskite system. XRD spectra of the perovskite films with different thickness was measured, as shown in Figure S2, two main characteristic diffraction peaks located at around $14^{\circ}$ (100 plane) and $29^{\circ}$ (200 plane) can be observed in all perovskite samples. Meanwhile, the position of diffraction peak (at the range of $12^{\circ} \sim 16^{\circ}$ ) shifts from $13.68^{\circ}$ to $13.88^{\circ}$ with decreasing perovskite layer thickness, the perovskite lattice is proved to be contracted. Thus, the thinner perovskite layer with smaller perovskite crystal size may be the main reason for the bluer PL emission. PLQY is reduced from $60.1 \%$ to $32.8 \%$ (excited by a $365 \mathrm{~nm}$ laser with a power 
density of $9.25 \mathrm{~mW} \mathrm{~cm}^{-2}$ ), and average PL lifetime is decreased from $17.3 \mathrm{~ns}$ to 15.0 ns (Figure 14c and Figure 14d). The remarkably decreased radiative decay rate $\left(\mathrm{k}_{\mathrm{r}}\right)$ and increased non-radiative decay rate $\left(\mathrm{k}_{\mathrm{nr}}\right)$ may be attributed to the increased defect density (Table S1). In contrast, with the decreased thickness of the perovskite film from $50 \mathrm{~nm}$ to $30 \mathrm{~nm}$, improved carrier mobility can be found, as confirmed by holeonly (Figure S15a) and electron-only (Figure S15b) devices of these perovskite films. Monochromatic EL devices were also fabricated by using these perovskite films for comparison (Figure S16, Table S2, Note S6). The valence bands (VB) of these perovskite films remain almost unchanged (Figure S1c and Figure S1d), indicating the impact on the hole injection barrier between different thickness perovskite films and TAPC layer can be ignored. Pure-red perovskite-based LEDs were also fabricated with a configuration of ITO/ m-PEDOT: PSS (30)/ perovskite (50/40/30 nm)/ TPBI $(30 \mathrm{~nm}) / \mathrm{CsF}(1.2 \mathrm{~nm}) / \mathrm{Al}(120 \mathrm{~nm})$ for comparison, and the fabricated devices were labeled as R1, R2 and R3, respectively. According to Figure S16, with decreasing perovskite layer thickness, their EL spectra show slight blue-shifted tendency, and the EQE value begins to decline, which is well coincidence with their increased surface defect density and reduced PLQY. In addition, the EL spectra of devices R2 and R3 still remain unchanged under various driving voltages. The detailed device parameters are summarized in Table S2.

\section{Note S6:}

\section{Optical simulation:}

For simulation process, the light outcoupling efficiency of device was measured via Fluxim and simulated by Setfos 5.1. For simplification, the device structure of Glass/

ITO/m-PEDOT: PSS (30 nm)/ Perovskite (50, 40 or $30 \mathrm{~nm}) /$ TPBI (x nm)/ Al (120 $\mathrm{nm}$ ) is used for simulation. The refractive index (n) and extinction coefficient $(\mathrm{k})$ of all the materials used in the simulation is displayed in Figure 18d. The $\mathrm{n}$ and $\mathrm{k}$ values of other functional layers are obtained from well-established simulation software database. PL spectrum used for light outcoupling efficiency simulation of the red 
perovskite LEDs was measured by the Setfos-Phelos integration of the Phelos system. It is supposed that all the layers used here are isotropic and the emitting layer does not absorb any light. The relative average contributions of all channels of the red perovskite LEDs are also shown in Figure 18a to Figure 18c. Indeed, a part of the light emitted in the substrate has undergone several transmission/reflection events in the substrate before escaping the device. When reflecting on the thin film stack a part of the light is absorbed, leading to a decrease of the outcoupled mode.

\section{Note S7:}

\section{Determination of the red component in white emission mainly from the electroluminescence of the perovskite layer:}

As shown in Figure S20a, we firstly fabricated the p-i-n heterojunction organic LEDs with a configuration of ITO/ m-PEDOT:PSS (30 nm)/ TAPC (5 nm)/ FIrpic (1 nm)/ BOCzph $(20 \mathrm{~nm}) /$ TPBI $(30 \mathrm{~nm}) / \mathrm{CsF}(1.2 \mathrm{~nm}) / \mathrm{Al}(120 \mathrm{~nm})$, then, the ITO substrates spin-coated with perovskite films were pasted on the glass surface of the devices by using a double-side adhesive tape. When the perovskite films were excited by UV light (365 nm), uniform and bright red PL emission can be observed. However, when the sky-blue light emission (vary from $100 \mathrm{~cd} \mathrm{~m}^{-2}$ to $2000 \mathrm{~cd} \mathrm{~m}^{-2}$ ) from the organic pi-n heterojunction LED pass through the perovskite films (30 nm to $50 \mathrm{~nm}$ ), only a dominant blue emission can be detected (Figure S20b to S20d), compared with a dominant red emission in white electroluminescent device. It is obvious that the red component is mainly from the electroluminescence of the perovskite layer. In addition, all test procedures were carried out in $\mathrm{N}_{2}$-filled golvebox, so it can exclude the influence of external enviorment caused rapid decomposition of the perovskite layers.

\section{Note S8:}

\section{Transient EL decay dynamics:}

Transient EL decay dynamics can be divided into four parts in chronological order, as shown in Figure S22. (i) Delay time, it is the time delay between the occurrence of 
pulse voltage and EL, holes and electrons just start to be injected into the device. (ii) Rising time, defects are being filled and the excited states are building up. (iii) Flat time, exciton concentration tends to be constant and gives a stable emission. (iv) Decay time, the remaining carriers are being consumed after turning off the pulse voltage. It is worth noting that the carriers trapped in the defects escape and recombine during this period, causing the overshoot effect, and the EL intensity shows a rapid increase after pulse voltage turning-off. Therefore, while keeping other conditions unchanged, the relative defect state density of the device can be obtained.

(a)
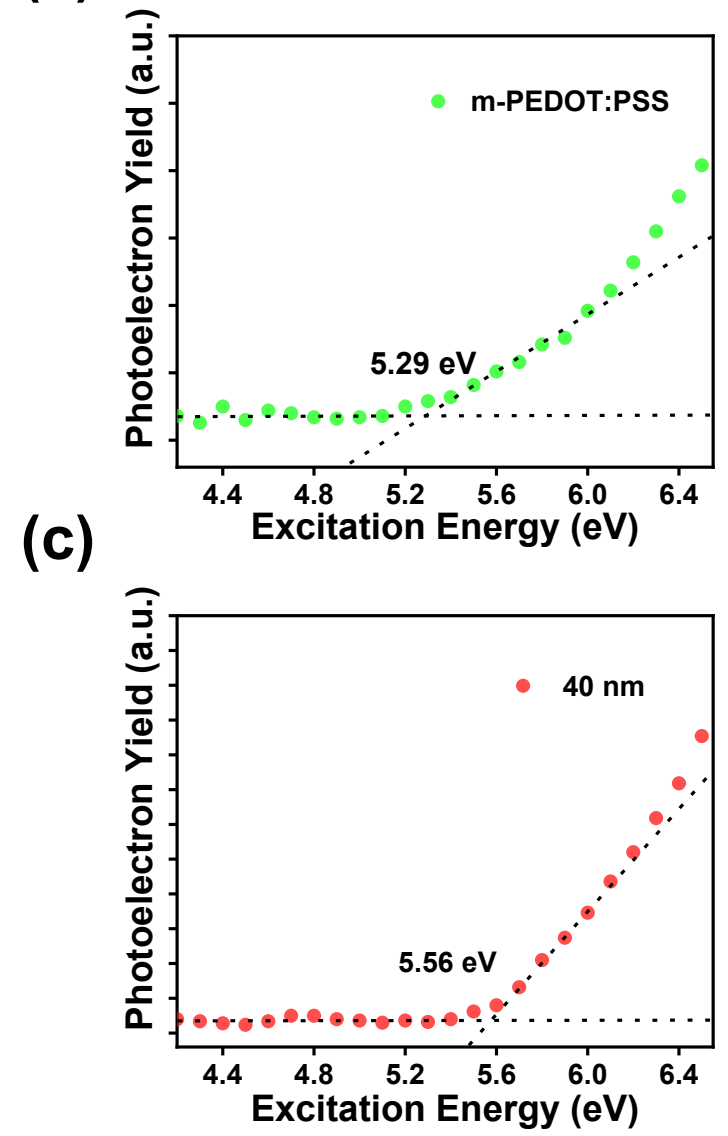

(b)

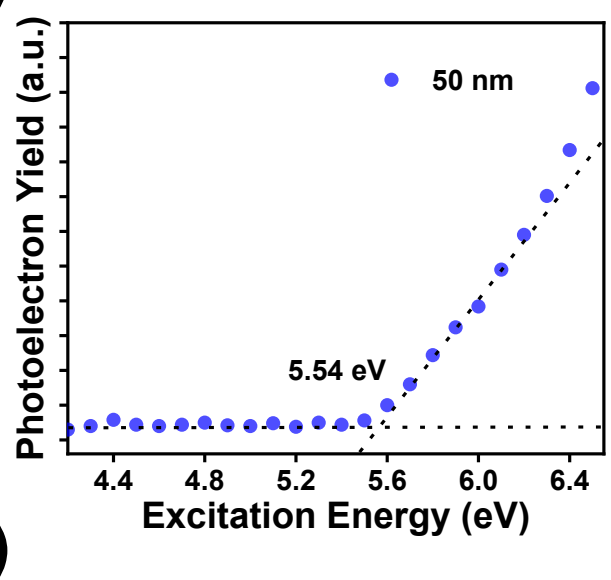

(d)

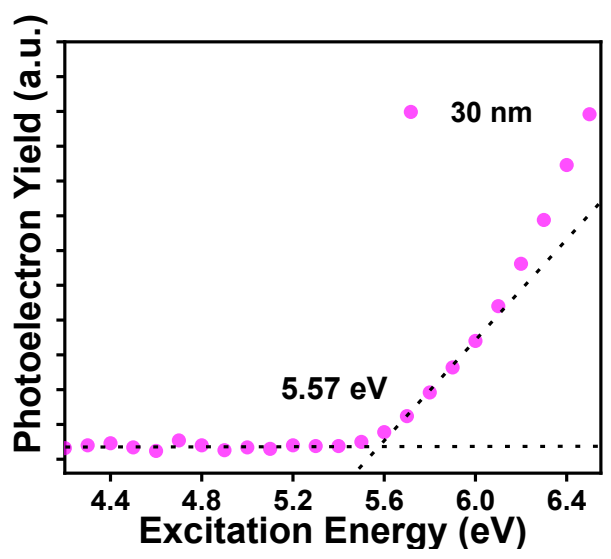

Figure S1. Atmospheric ultraviolet photoelectron spectroscopies of (a) m-PEDOT: PSS spin-coated on ITO substrate, (b) perovskite $(50 \mathrm{~nm})$, (c) perovskite $(40 \mathrm{~nm})$ and (d) perovskite $(30 \mathrm{~nm})$ spin-coated on ITO/m-PEDOT: PSS. 


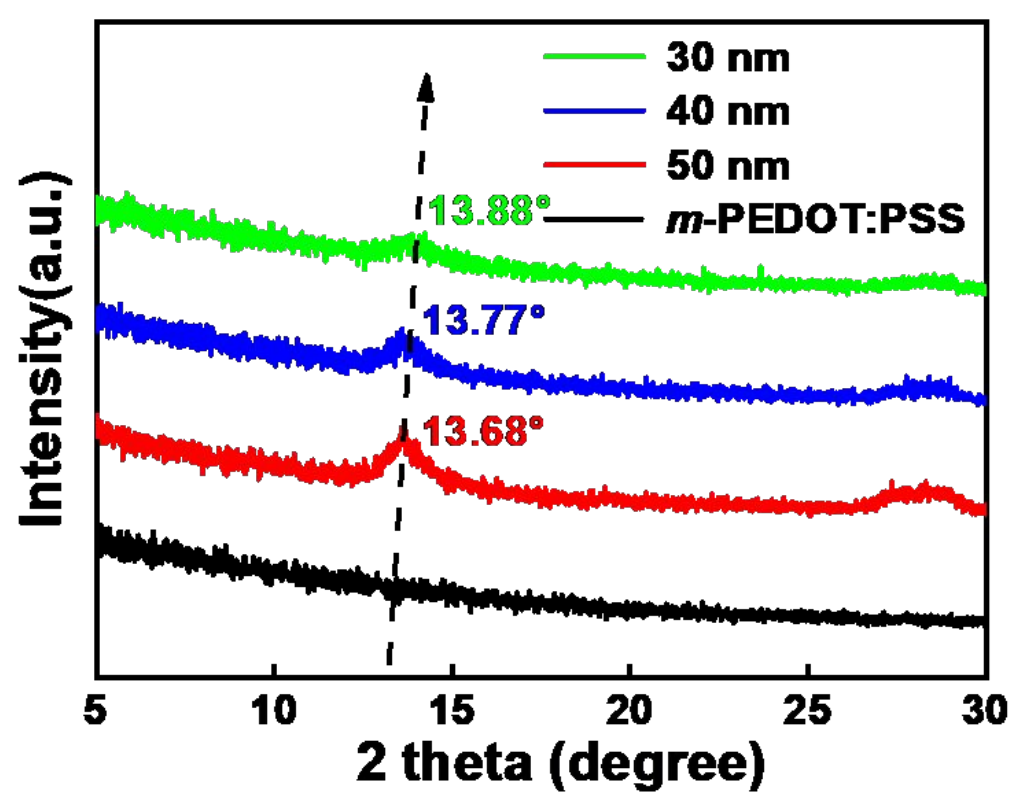

Figure S2. XRD spectra of the perovskite films with different thickness spin-coated on silicon substrate/ m-PEDOT: PSS (silicon substrate/ m-PEDOT: PSS as a control group).

(a)

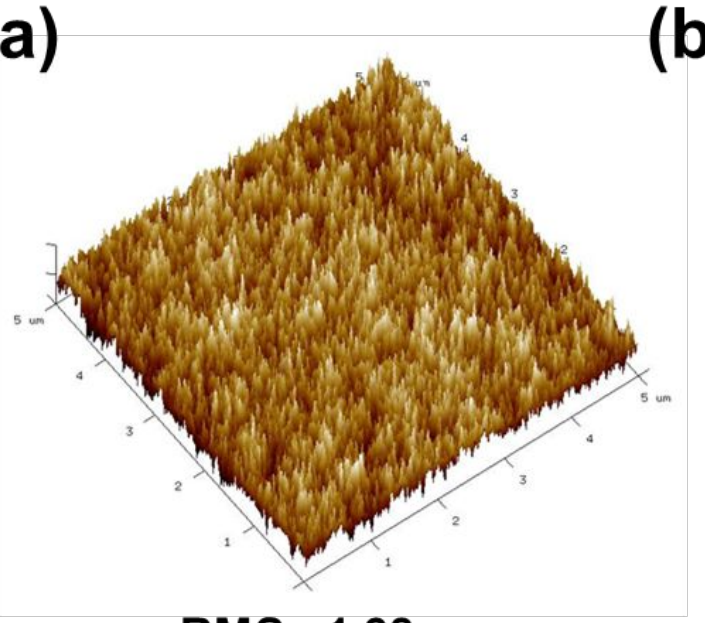

(b)

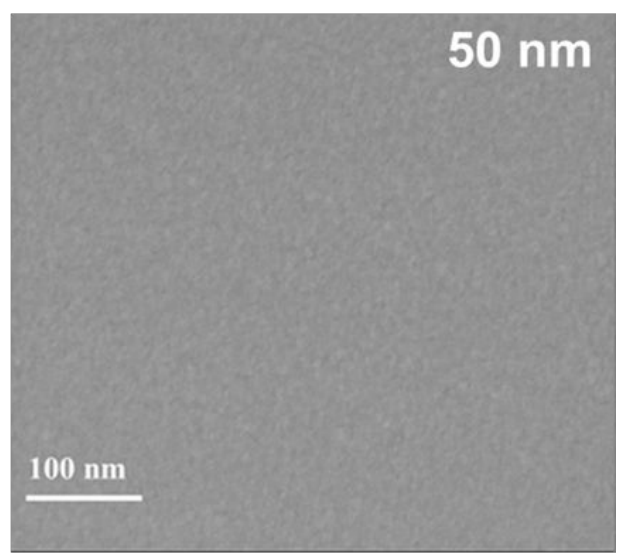

\section{RMS $=1.38 \mathrm{~nm}$}

Figure S3. (a) Top-view AFM image of ITO/ m-PEDOT: PSS/ perovskite (50 nm) and (b) corresponding top-view SEM image (right). 


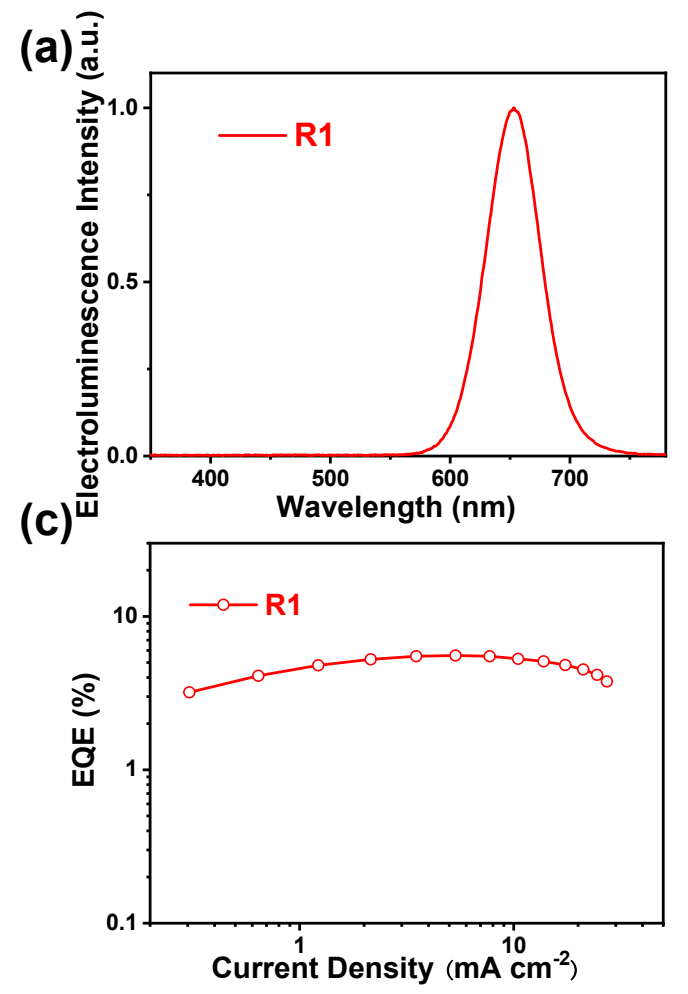

(b)
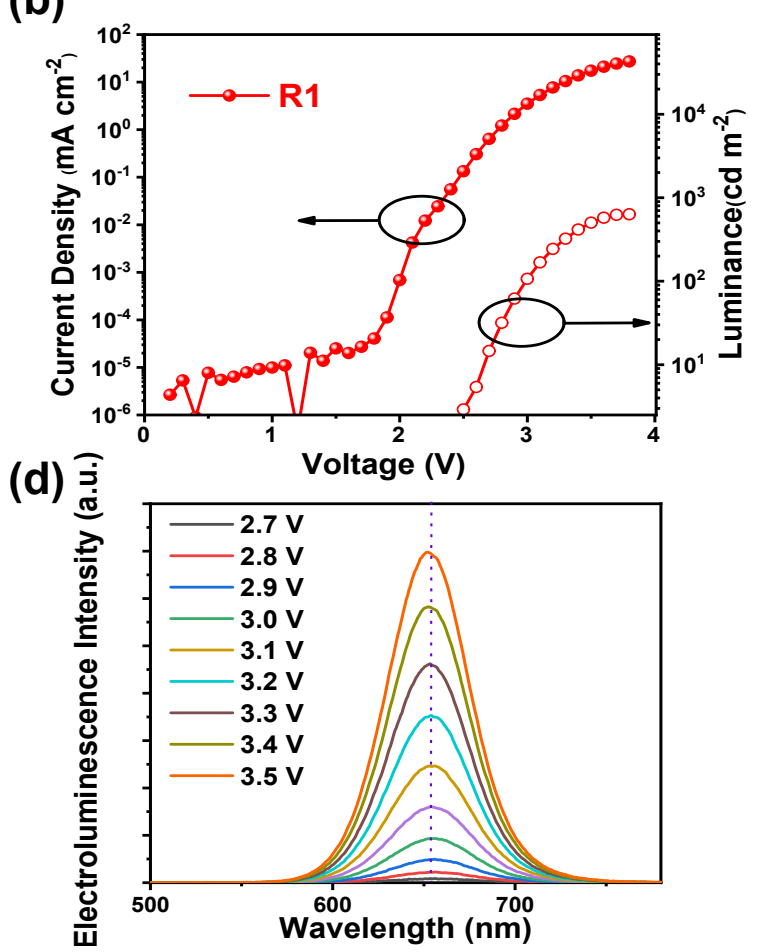

Figure S4. (a) Electroluminescence (EL) spectrum, (b) current density-voltageluminance $(J-V-L)$ and (c) external quantum efficiency-current density (EQE-J) characteristics of device R1. (d) EL spectra of device R1 under different driving voltages.

(a)

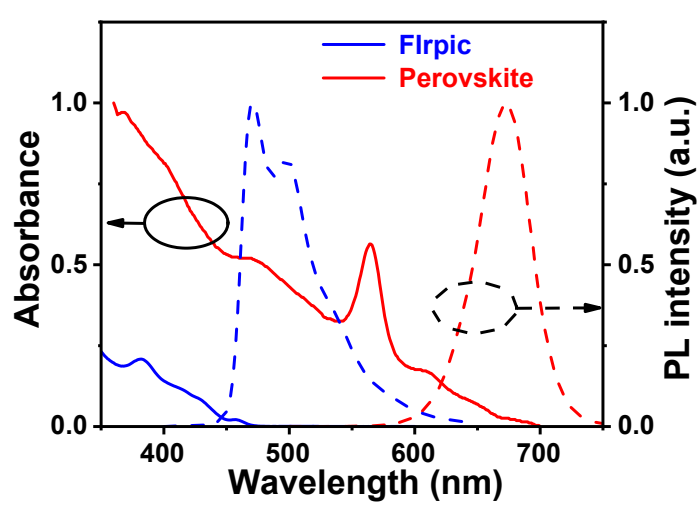

(b)

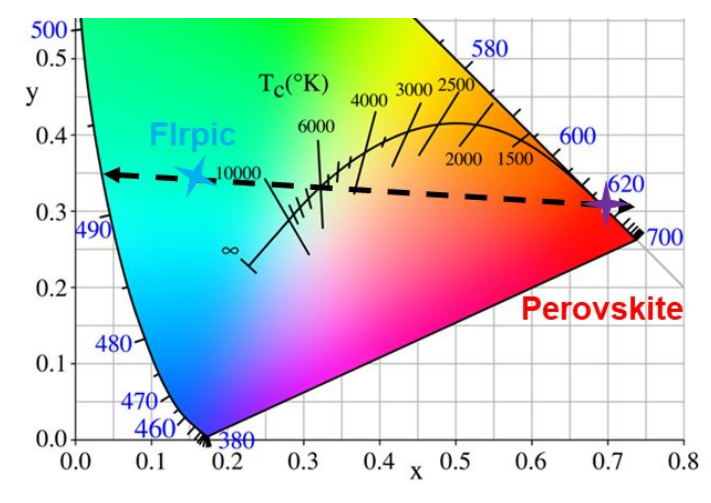

Figure S5. (a) UV-vis absorption (solid lines) and PL spectra (dashed lines) of FIrpic and perovskite in neat films (at room temperature of $298 \mathrm{~K}$ ). (b) CIE 1931 chromaticity coordinates of FIrpic and perovskite in their EL devices and their connection line (black). 


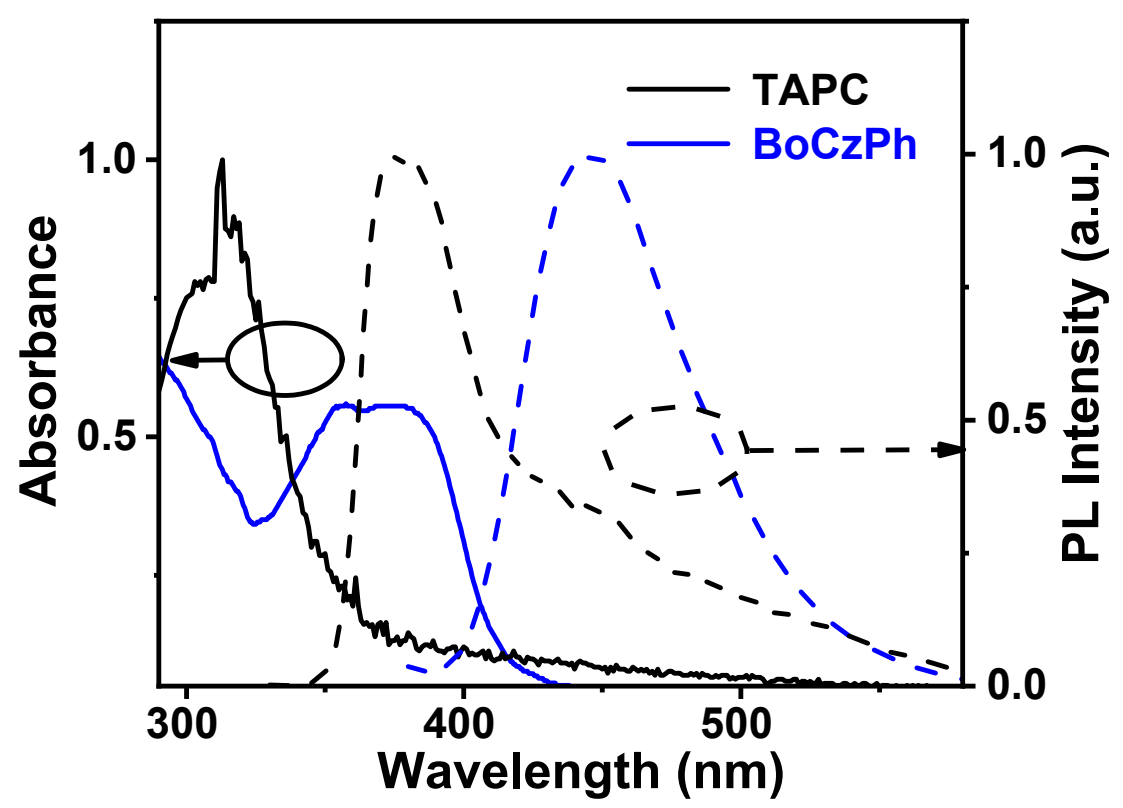

Figure S6. UV-vis absorption (solid lines) and PL spectra (dashed lines) of TAPC and $\mathrm{BOCzPh}$ in neat films measured at $298 \mathrm{~K}$.

(a)

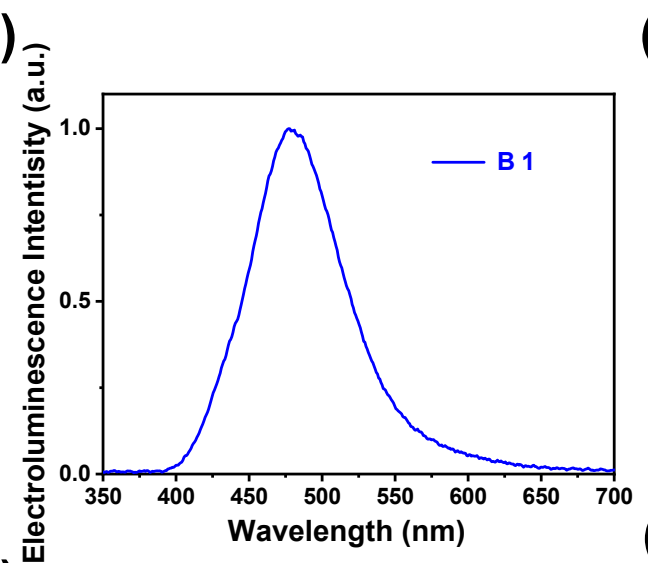

(c)

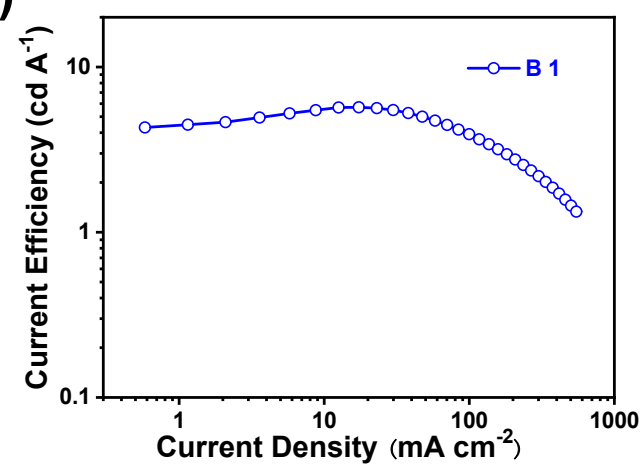

(b)

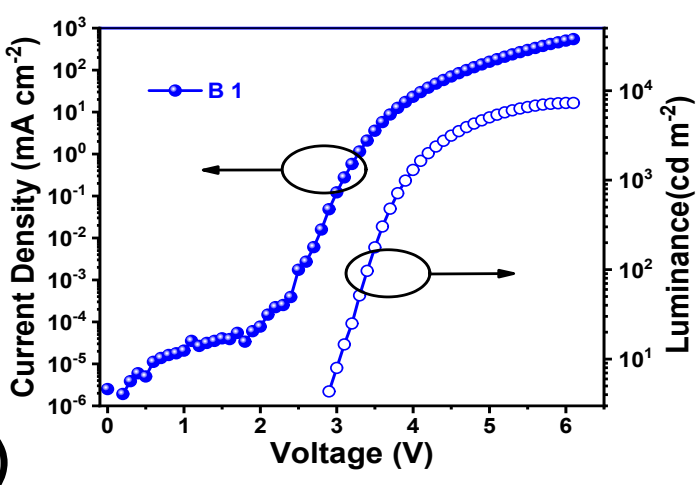

(d)

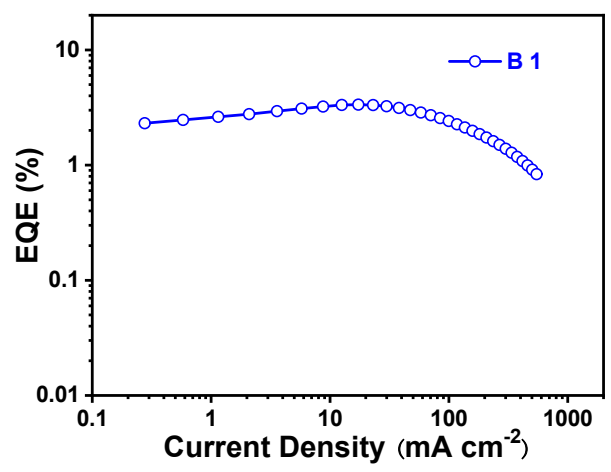

Figure S7. (a) Electroluminescence (EL) spectrum, (b) current density-voltageluminance $(J-V-L)$, (c) current efficiency-current density $(C E-J)$ and (d) external quantum efficiency-current density $(E Q E-J)$ characteristics of device B1. 
(a)

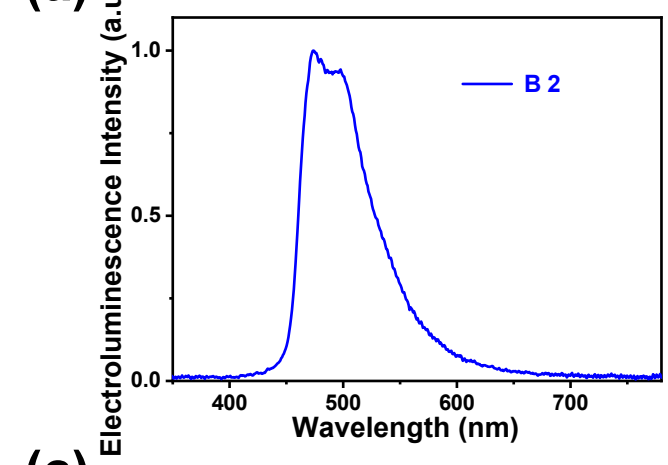

(c)

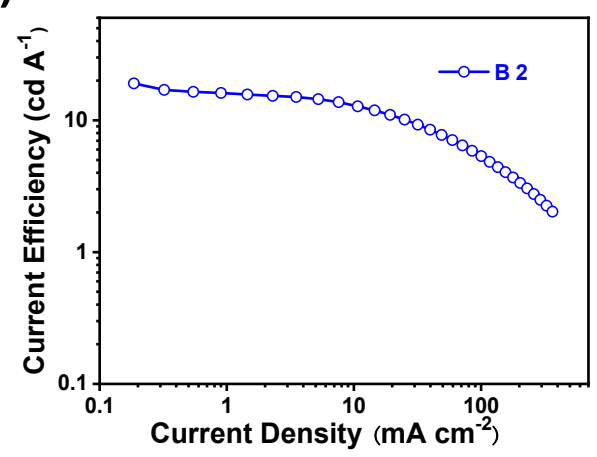

(b)

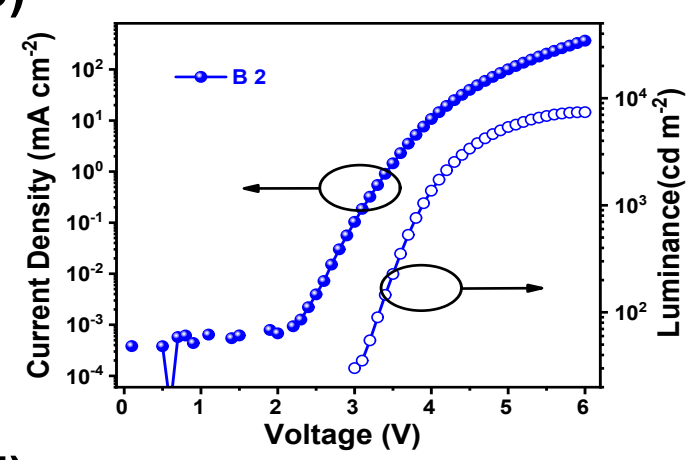

(d)

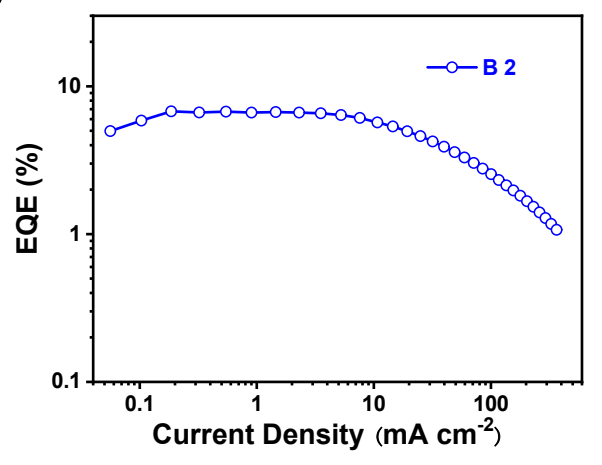

Figure S8. (a) Electroluminescence (EL) spectrum, (b) current density-voltageluminance $(J-V-L)$, (c) current efficiency-current density $(C E-J)$ and (d) external quantum efficiency-current density $(E Q E-J)$ characteristics of device B2. 
(a) $\bar{\exists}$

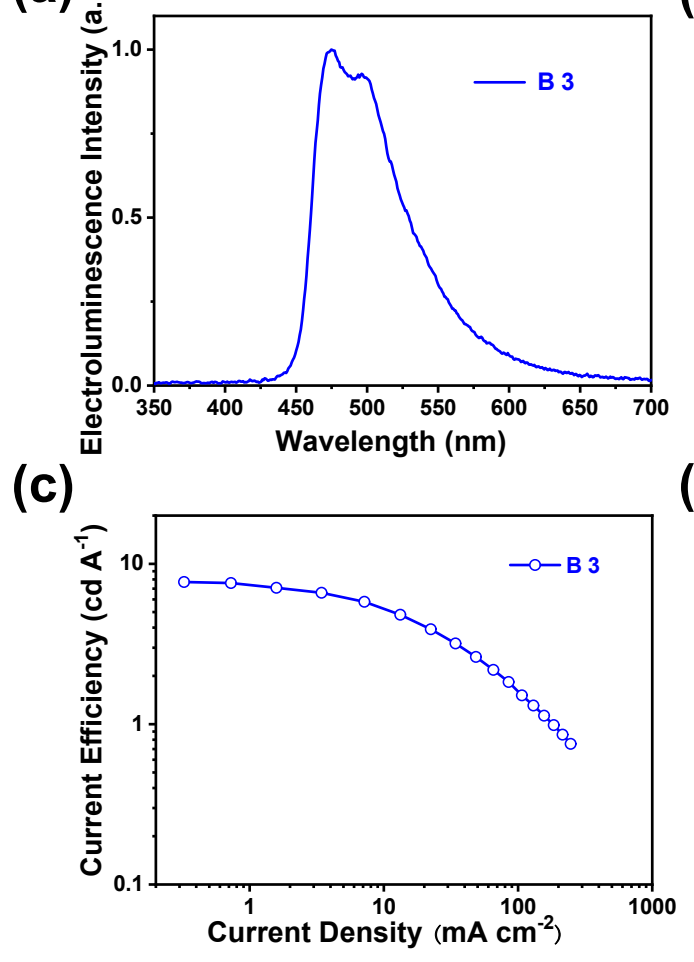

(b)

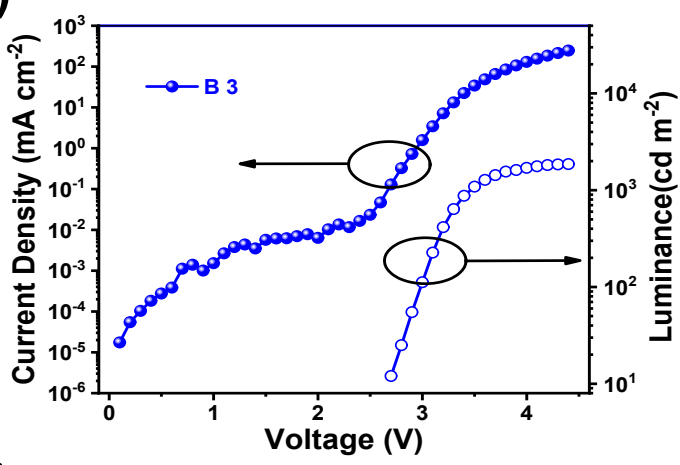

(d)

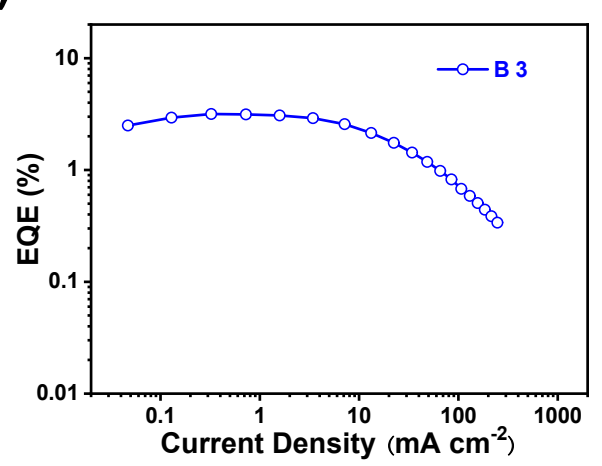

Figure S9. (a) Electroluminescence (EL) spectrum, (b) current density-voltageluminance $(J-V-L)$, (c) current efficiency-current density $(C E-J)$ and (d) external quantum efficiency-current density $(E Q E-J)$ characteristics of device B3. 
(a)

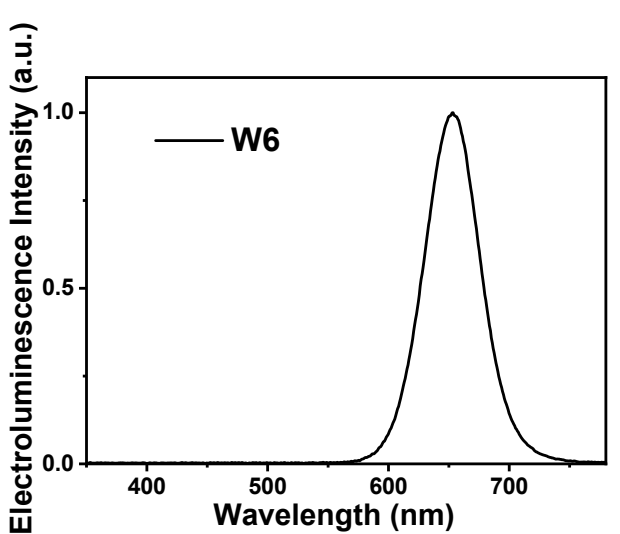

(c)

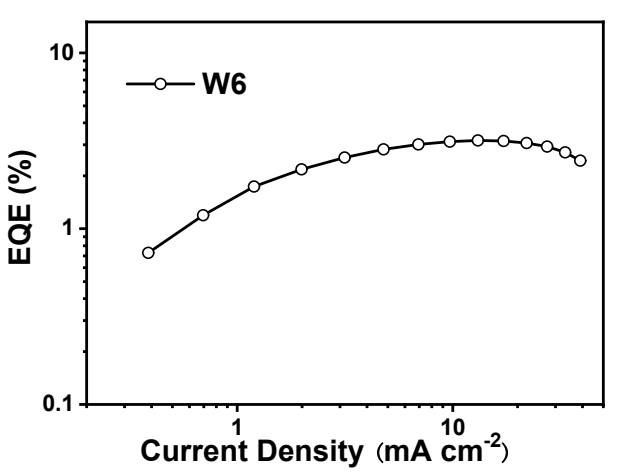

(b)

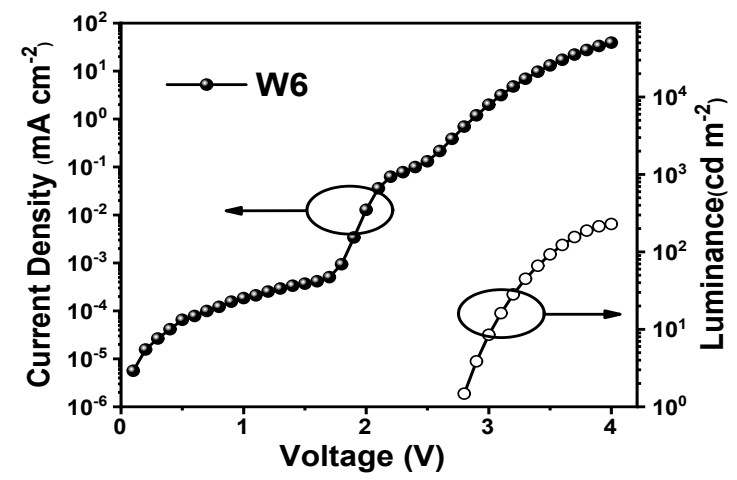

Figure S10. (a) Electroluminescence (EL) spectrum, (b) current density-voltageluminance $(J-V-L)$ and (c) external quantum efficiency-current density (EQE-J) characteristics of device W6.

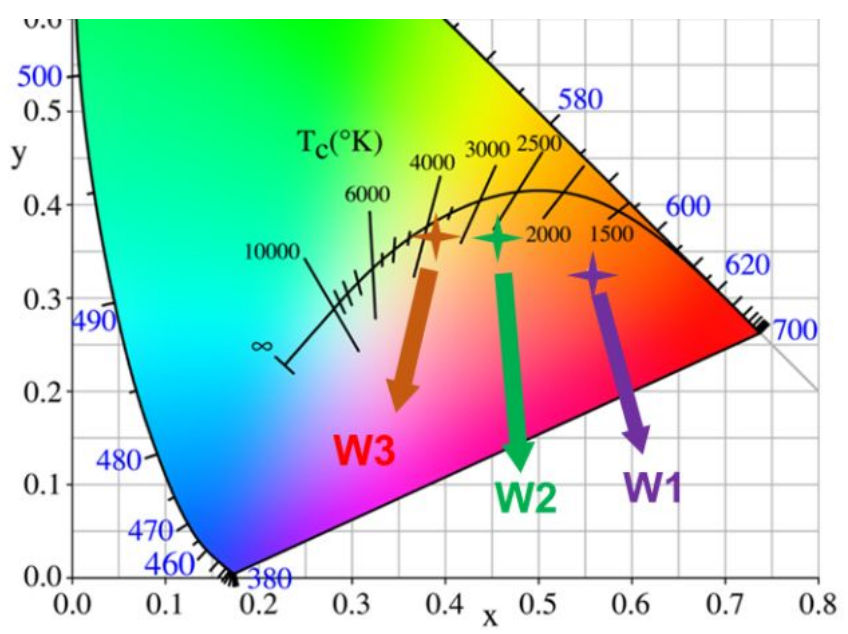

Figure S11. CIE 1931 chromaticity coordinates of devices W1, W2 and W3. 


\section{Device W5}

\section{$200 \mathrm{~nm}$}

Figure S12. Cross-sectional SEM images of device W5.

(a)

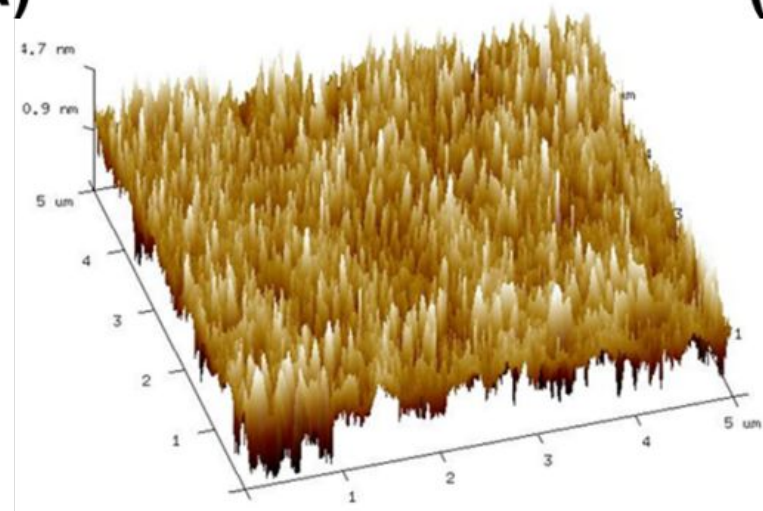

(c)

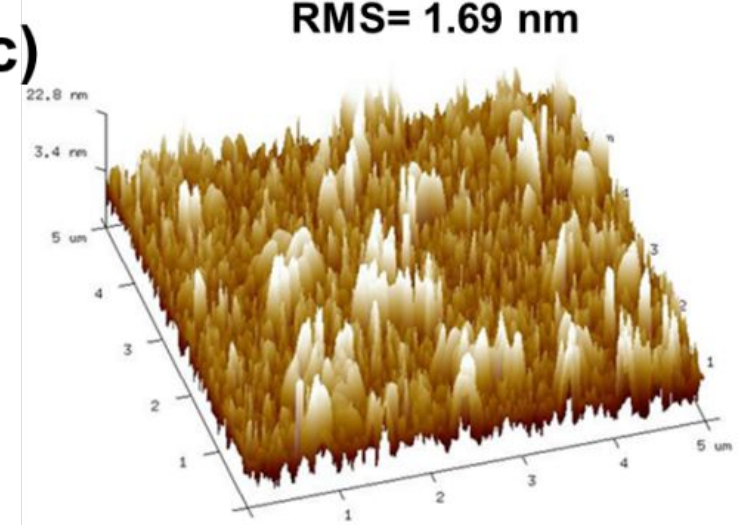

RMS $=2.11 \mathrm{~nm}$ (b)

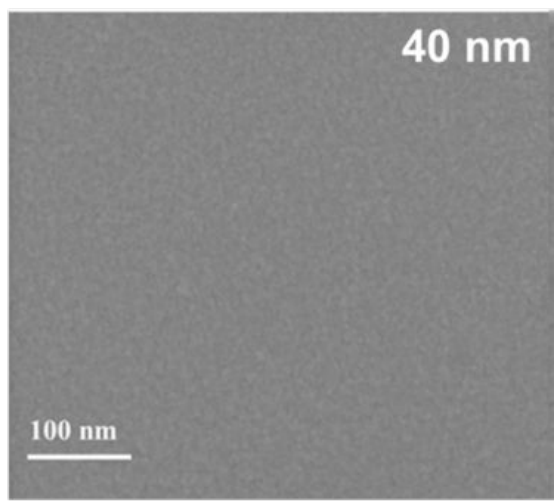

(d)

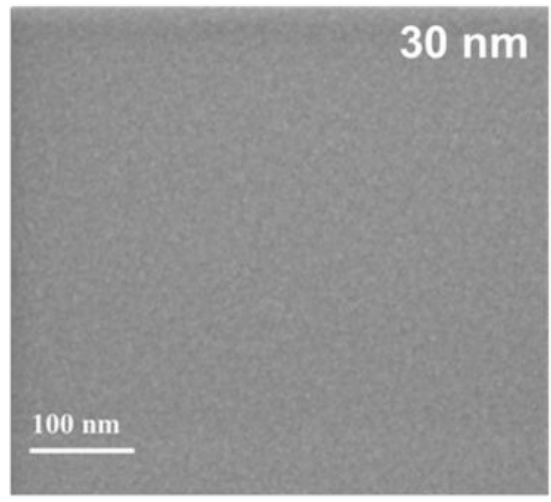

Figure S13. Top-view AFM images of (a) perovskite (40 nm) and (c) perovskite (30 $\mathrm{nm})$ spin-coated on ITO/m-PEDOT: PSS, and corresponding top-view SEM images of (b) and (d), respectively (right). 

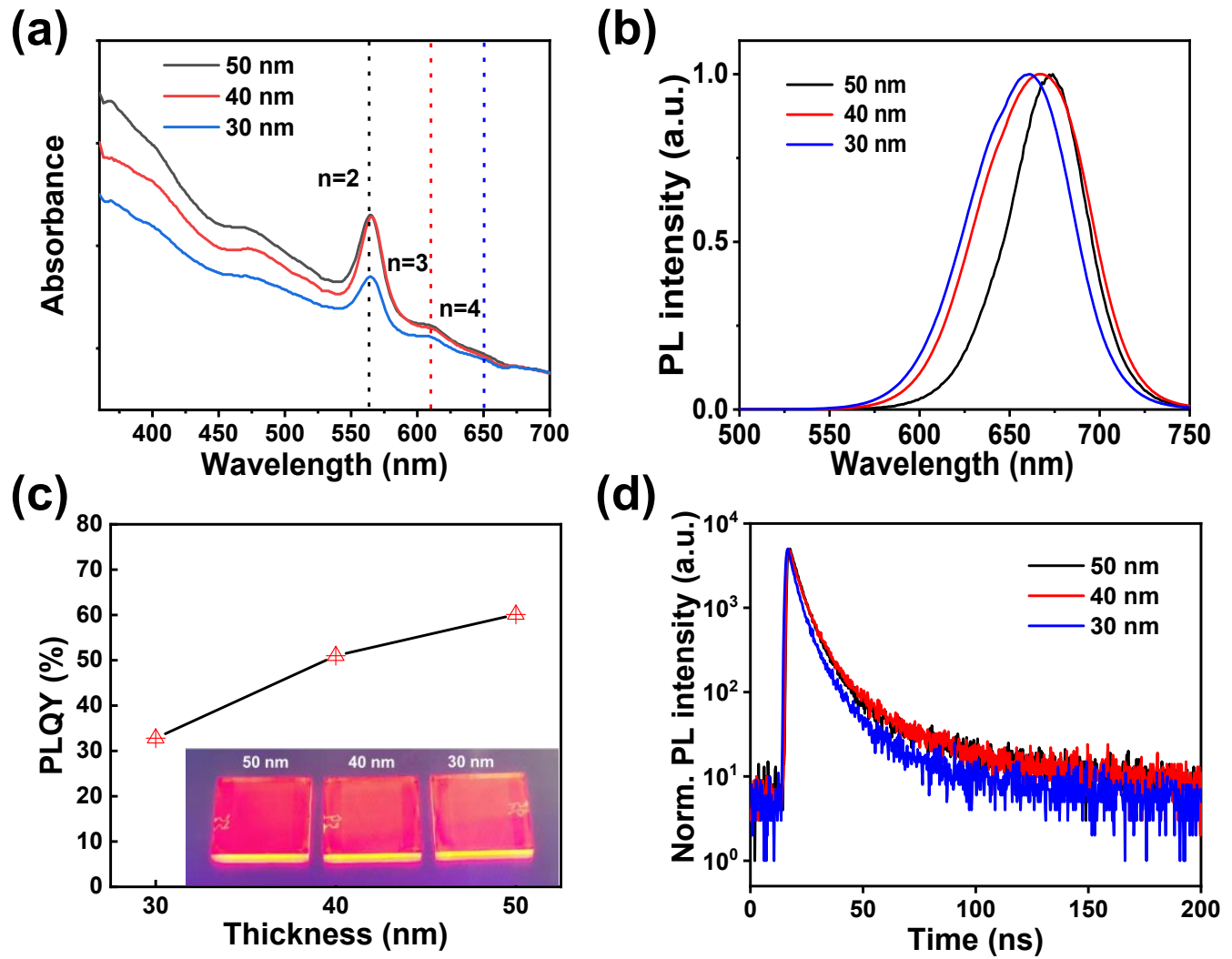

Figure 14. (a) UV-vis absorption spectra, (b) PL spectra, (c) PLQYs and photograph of the corresponding samples under $365 \mathrm{~nm}$ UV light as the inset, and (d) timeresolved PL decay (TRPL) curves of the perovskite films with different thickness.

(a)

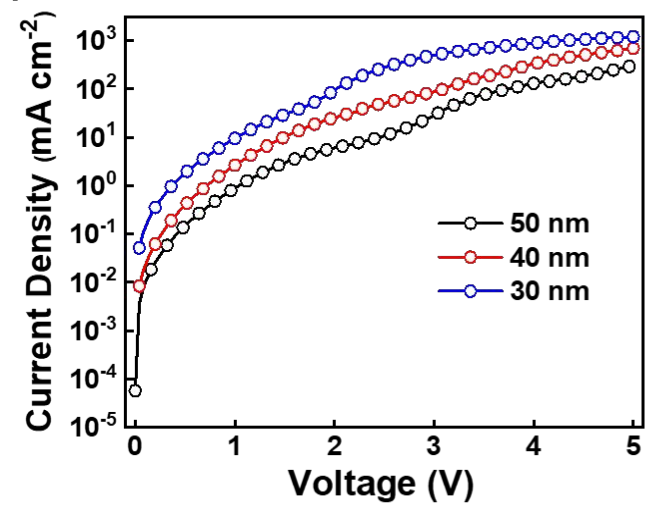

(b)

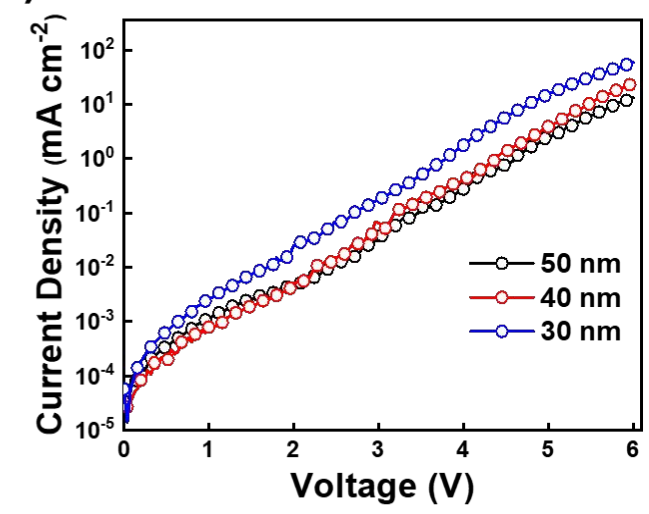

Figure S15. (a) $J-V$ characteristics of hole-only device with an architecture of ITO/ m-PEDOT: PSS (30 nm)/ perovskite (50, 40 and $30 \mathrm{~nm}) / \mathrm{MoO}_{3}(20 \mathrm{~nm}) / \mathrm{AL}(120$ $\mathrm{nm})$. (b) $J-V$ characteristics of electron-only device with an architecture of ITO/ $\mathrm{ZnO} / \mathrm{PEI}(30 \mathrm{~nm}) /$ perovskite $(50,40$ and $30 \mathrm{~nm}) / \mathrm{TPBI}(30 \mathrm{~nm}) / \mathrm{CsF}(1.2 \mathrm{~nm}) / \mathrm{AL}$ 
(120 nm).

(a)

(c)
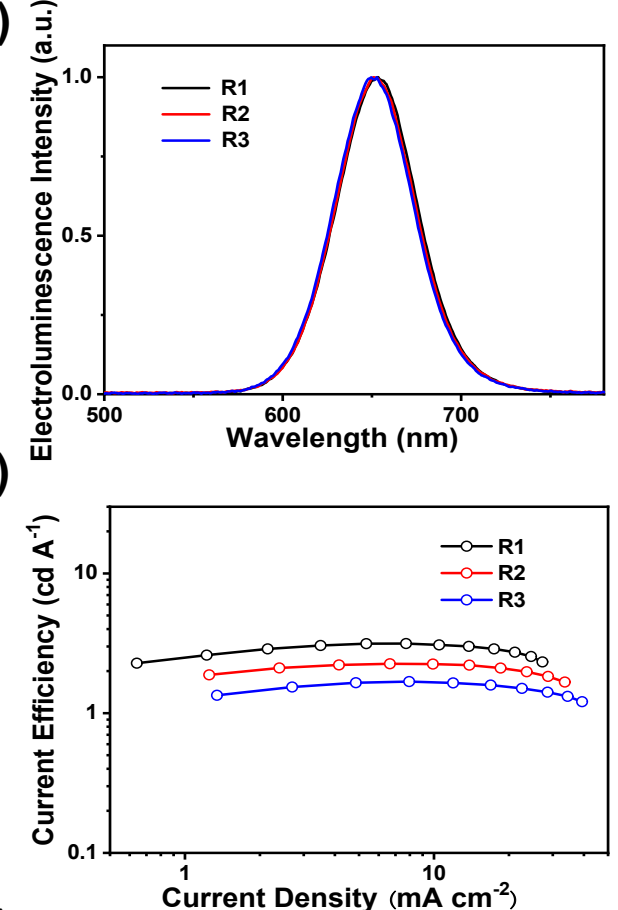

(e)

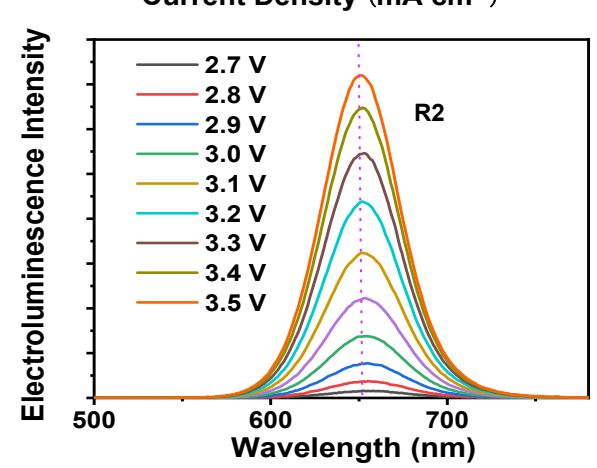

(b)

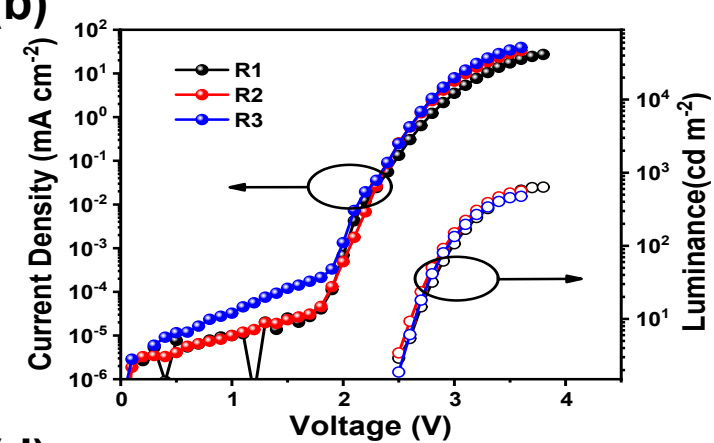

(d)

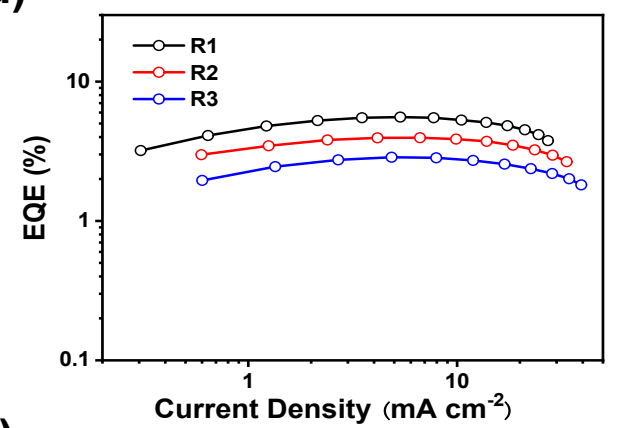

(f)

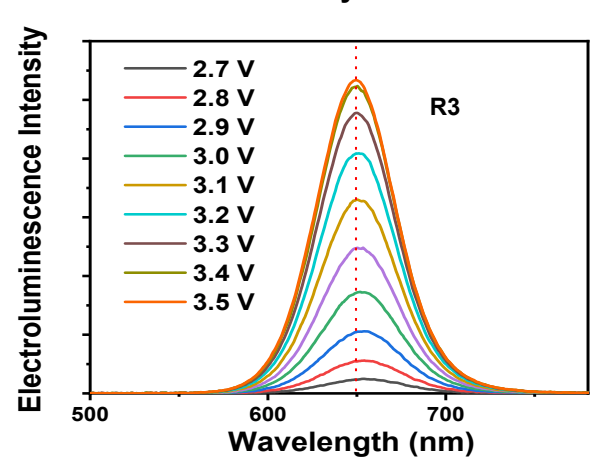

Figure S16. (a) EL spectra, (b) $J-V-L$, (c) $C E-J$ and (d) $E Q E-J$ curves of devices R1, R2 and R3. EL spectra of devices (e) R2 and (f) R3 under different applied bias. 


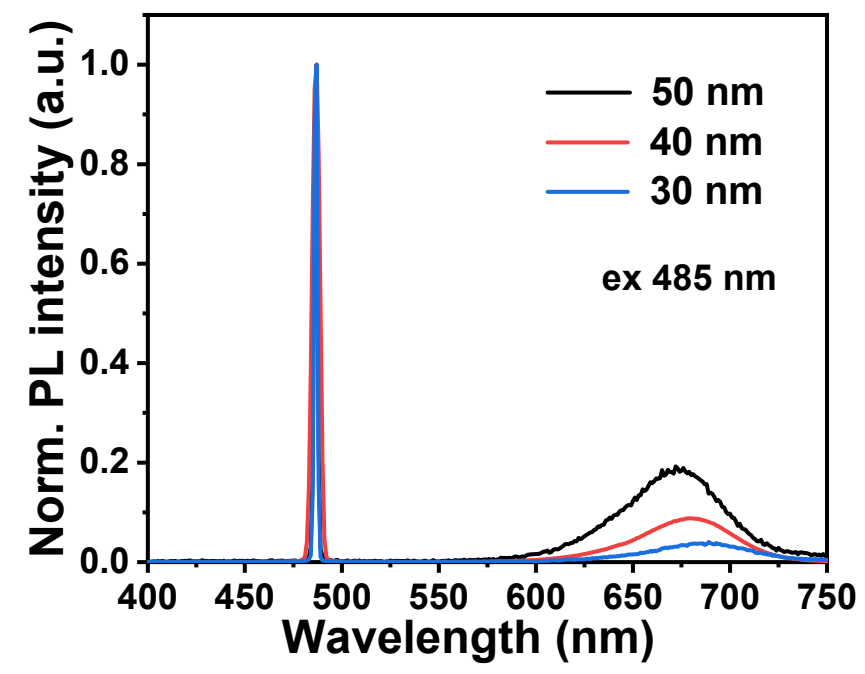

Figure S17. Detected PL spectra (from $400 \mathrm{~nm}$ to $750 \mathrm{~nm}$ ) of the perovskite films (50/40/ $30 \mathrm{~nm})$ spin-coated onto ITO/ m-PEDOT: PSS excited by incident blue light $(485 \mathrm{~nm})$ with the same intensity.

(a)

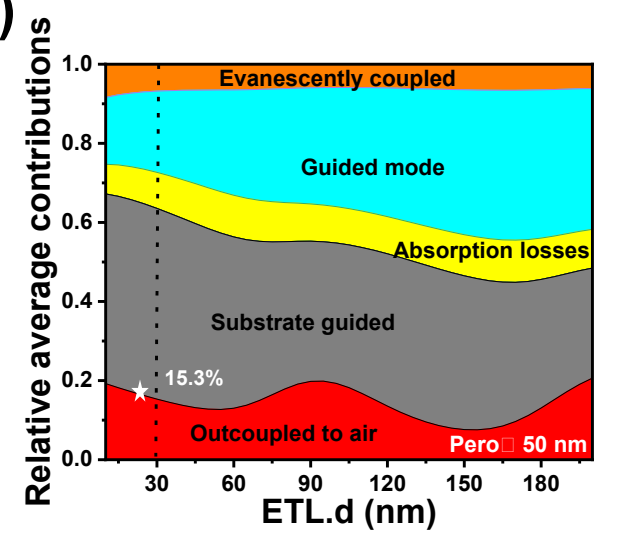

(c)

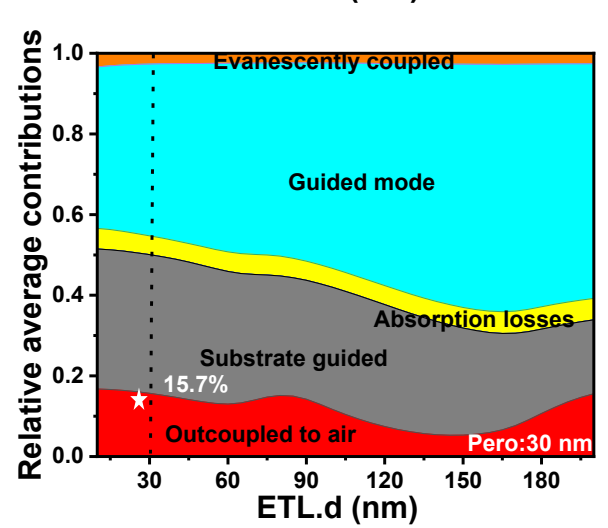

(b)

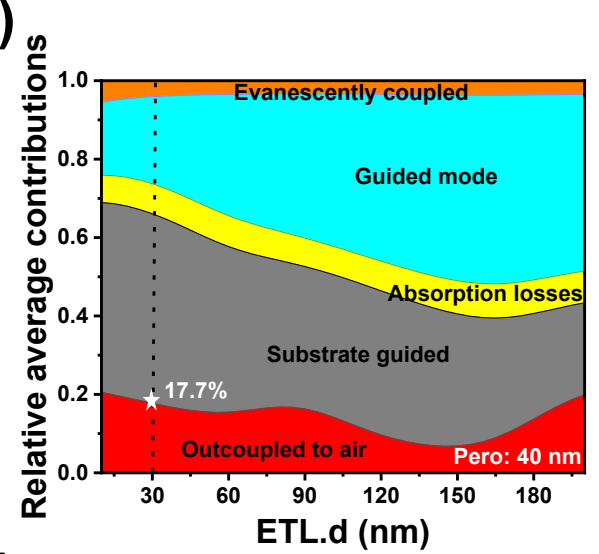

(d)

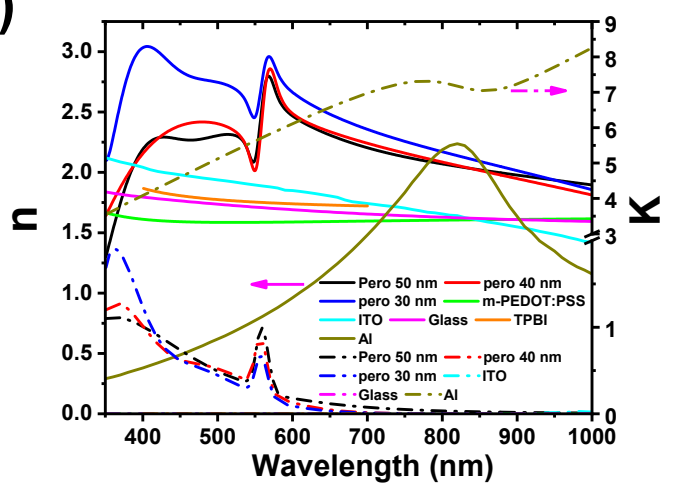

Figure S18. The simulated photon distribution of all loss channels in dependence of the ETL thickness (TPBI) in the red perovskite LEDs with (a) 50-nm (b) 40-nm (c) 30-nm perovskite layer as EML. (d) The refractive index (n) and extinction coefficient $(\mathrm{k})$ of all the materials used in simulation. 


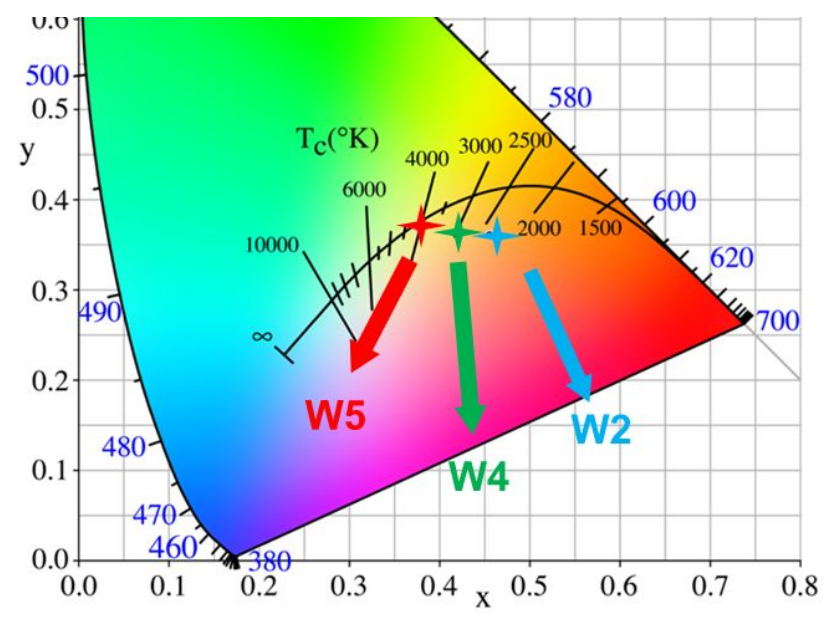

Figure S19. CIE 1931 chromaticity coordinates of devices W2, W4 and W5.

(a)

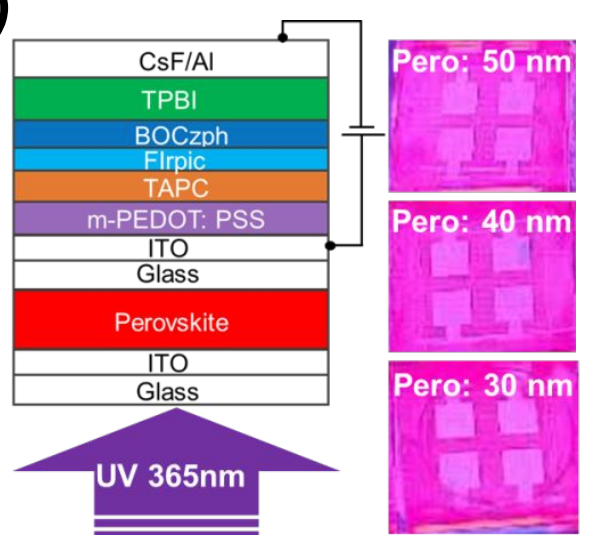

(c)

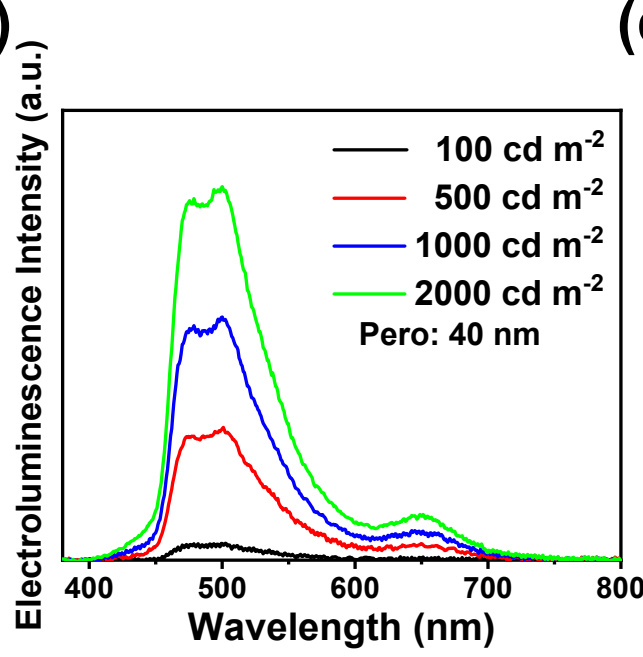

(b)

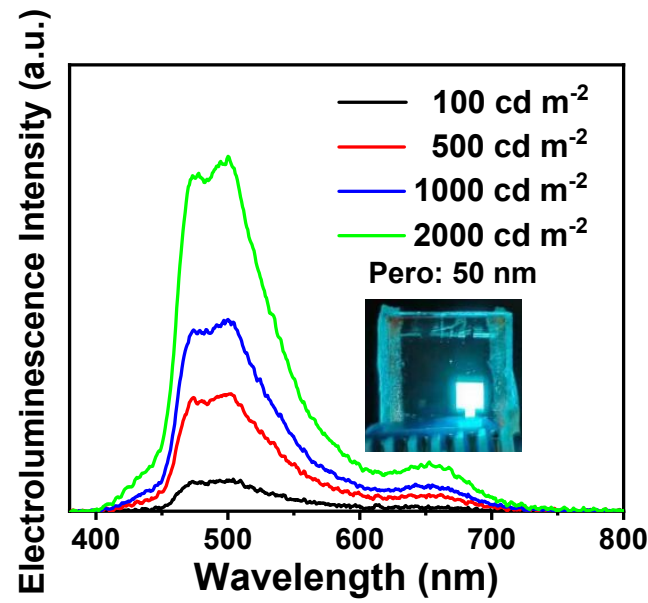

(d)

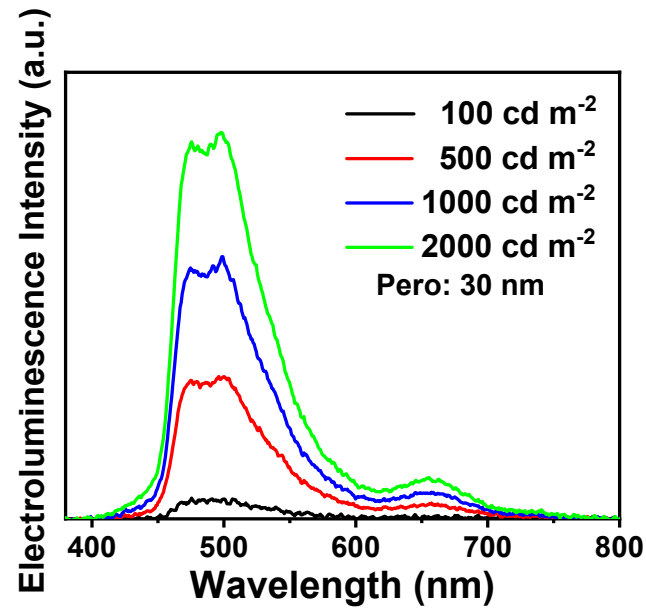

Figure S20. (a) Schematic description of the different thickness perovskite films excited by a sky-blue p-i-n heterojunction organic LED, the right side are the photographs of the perovskite films under the excitation of UV light (365 nm). EL 
spectra of the different thickness perovskite films (b) $50 \mathrm{~nm}$ (Inset: photograph of device in working), (c) 40 and (d) $30 \mathrm{~nm}$ were excited by a sky-blue p-i-n heterojunction organic LED under different brightness.

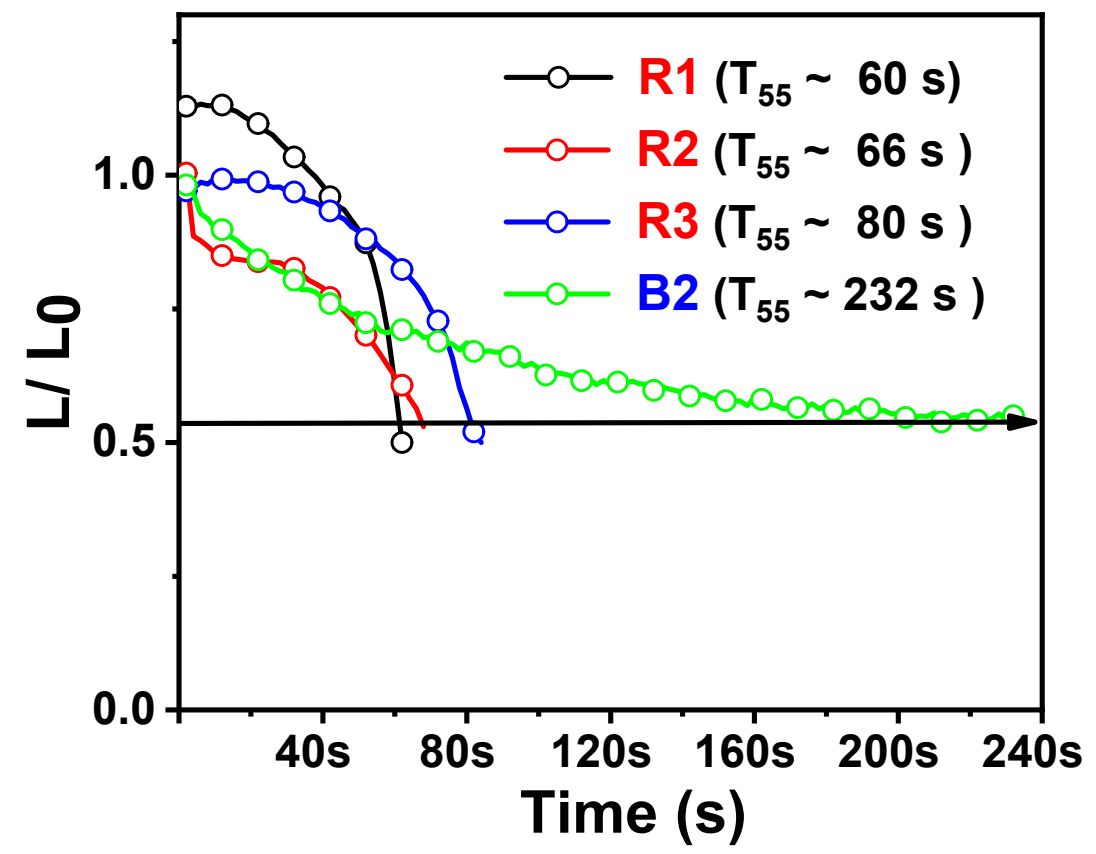

Figure S21. The operating lifetimes of devices R1, R2, R3 and B2 at the initial brightness of $100 \mathrm{~cd} \mathrm{~m}^{-2}$.

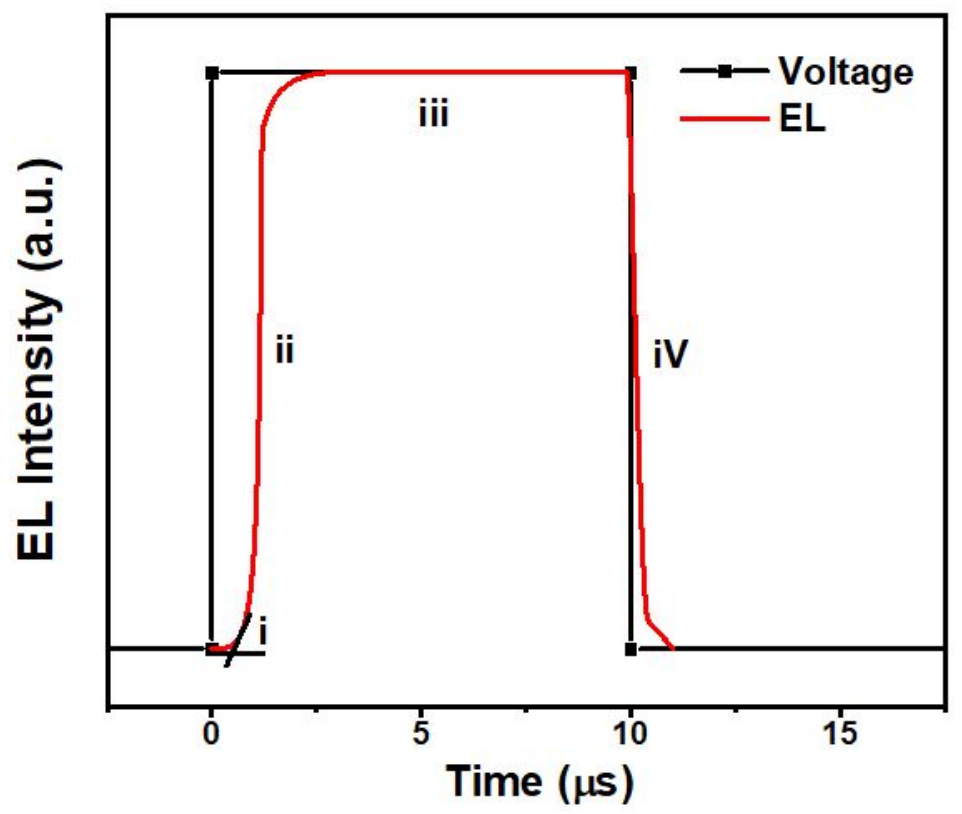

Figure S22. Schematic representations of the transient EL decay and pulse voltage. 


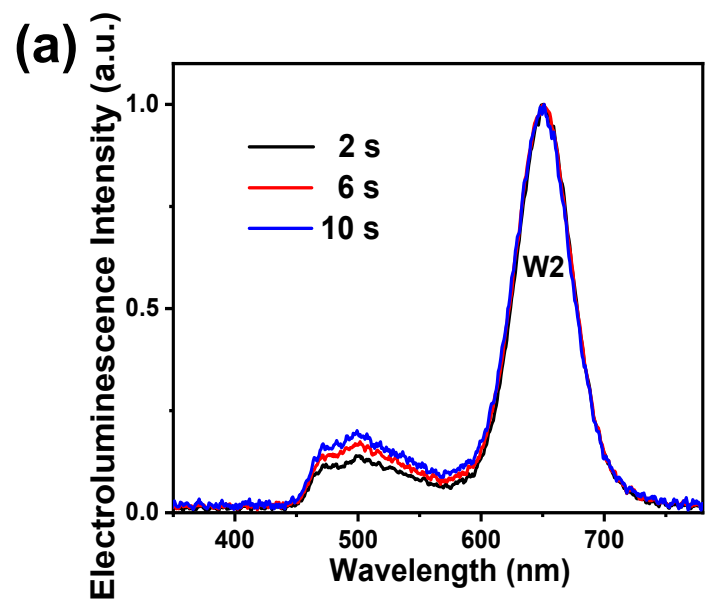

(b)

(c)
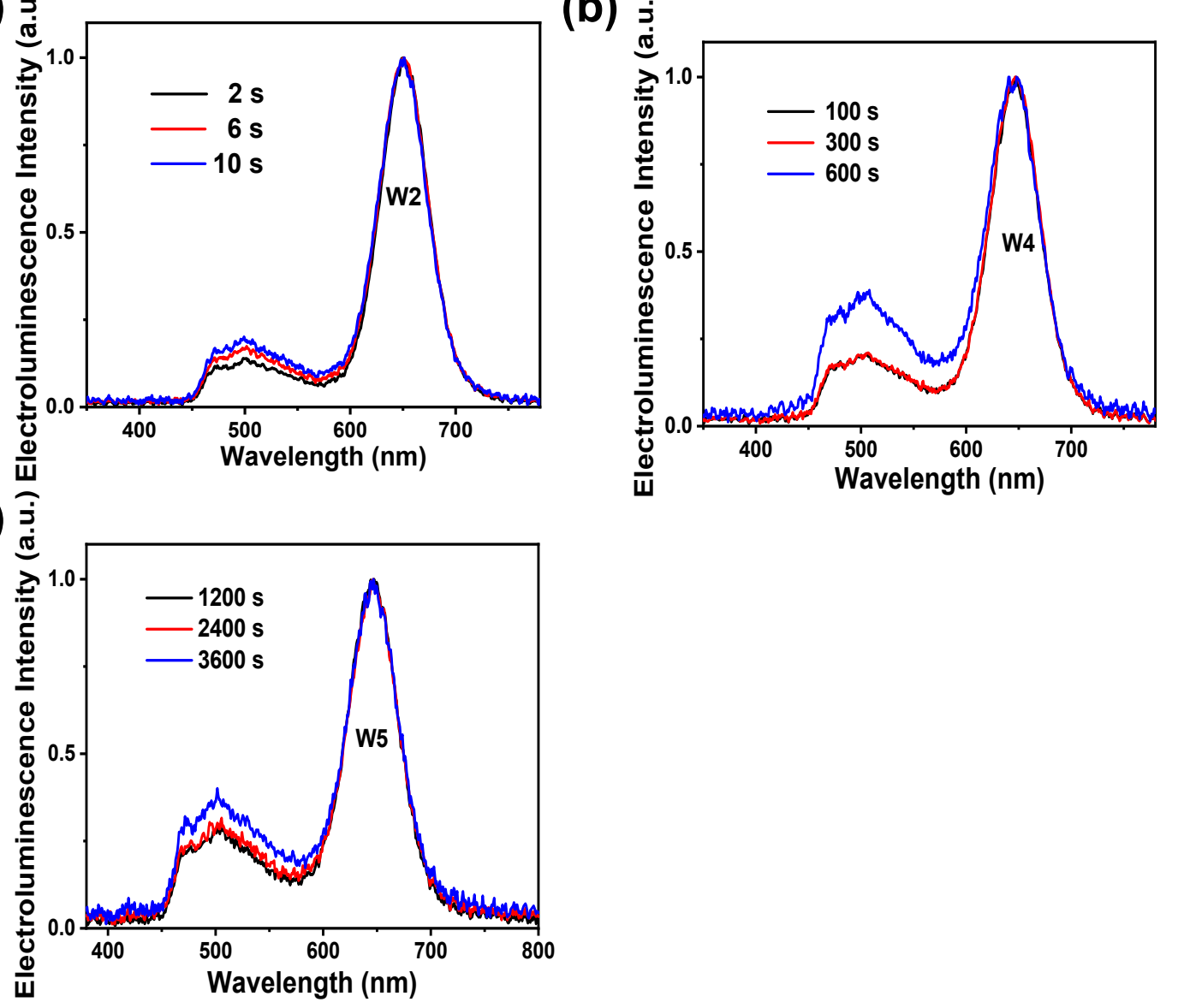

Figure S23. The EL spectra of devices (a) W2 (b) W4 and (c) W5 under different operating times driven at the initial brightness of $100 \mathrm{~cd} \mathrm{~m}^{-2}$. 


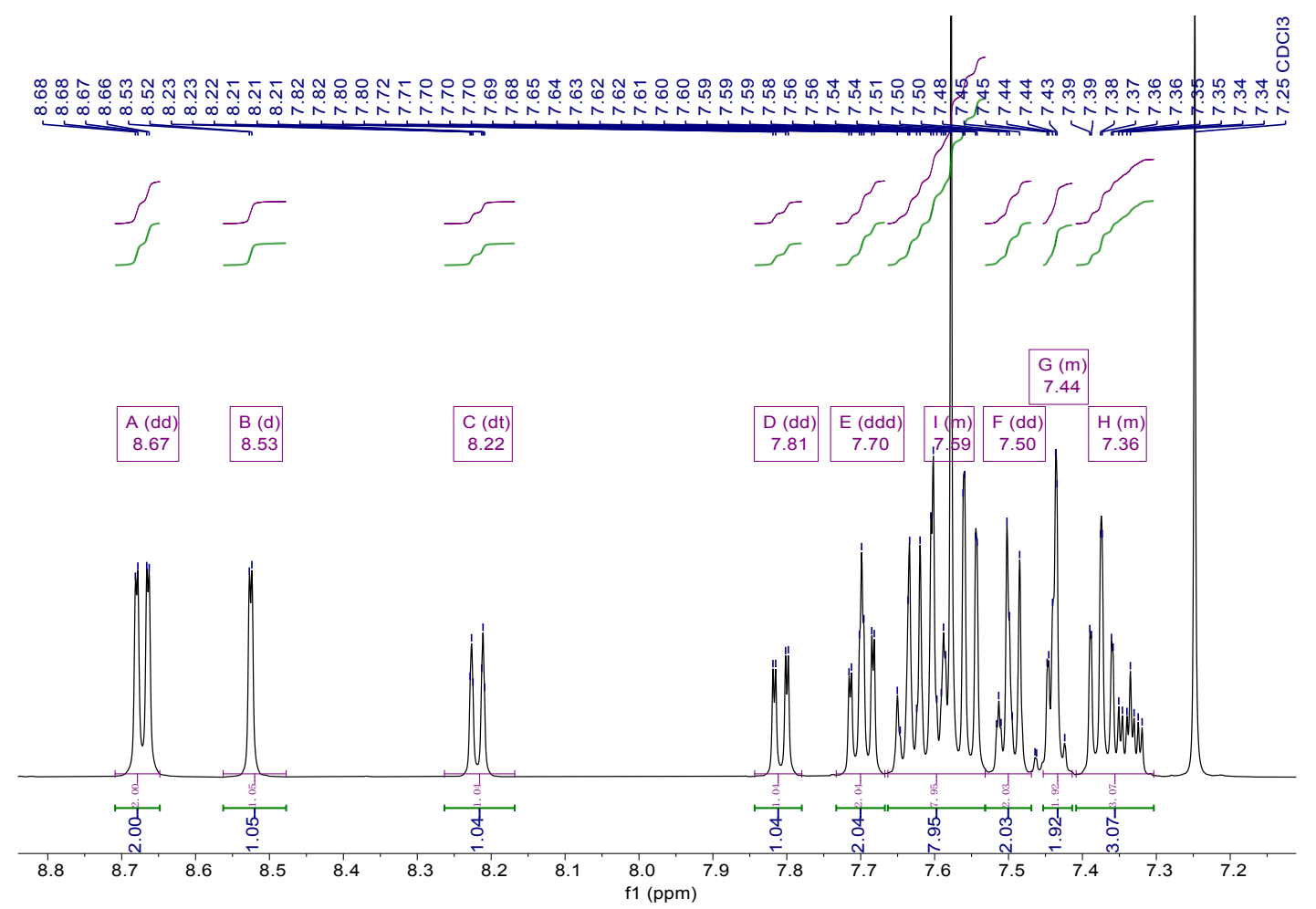

Figure S24. ${ }^{1} \mathrm{H}-\mathrm{NMR}$ spectrum of BOCzPh $(500 \mathrm{MHz}$, chloroform- $d$ ).

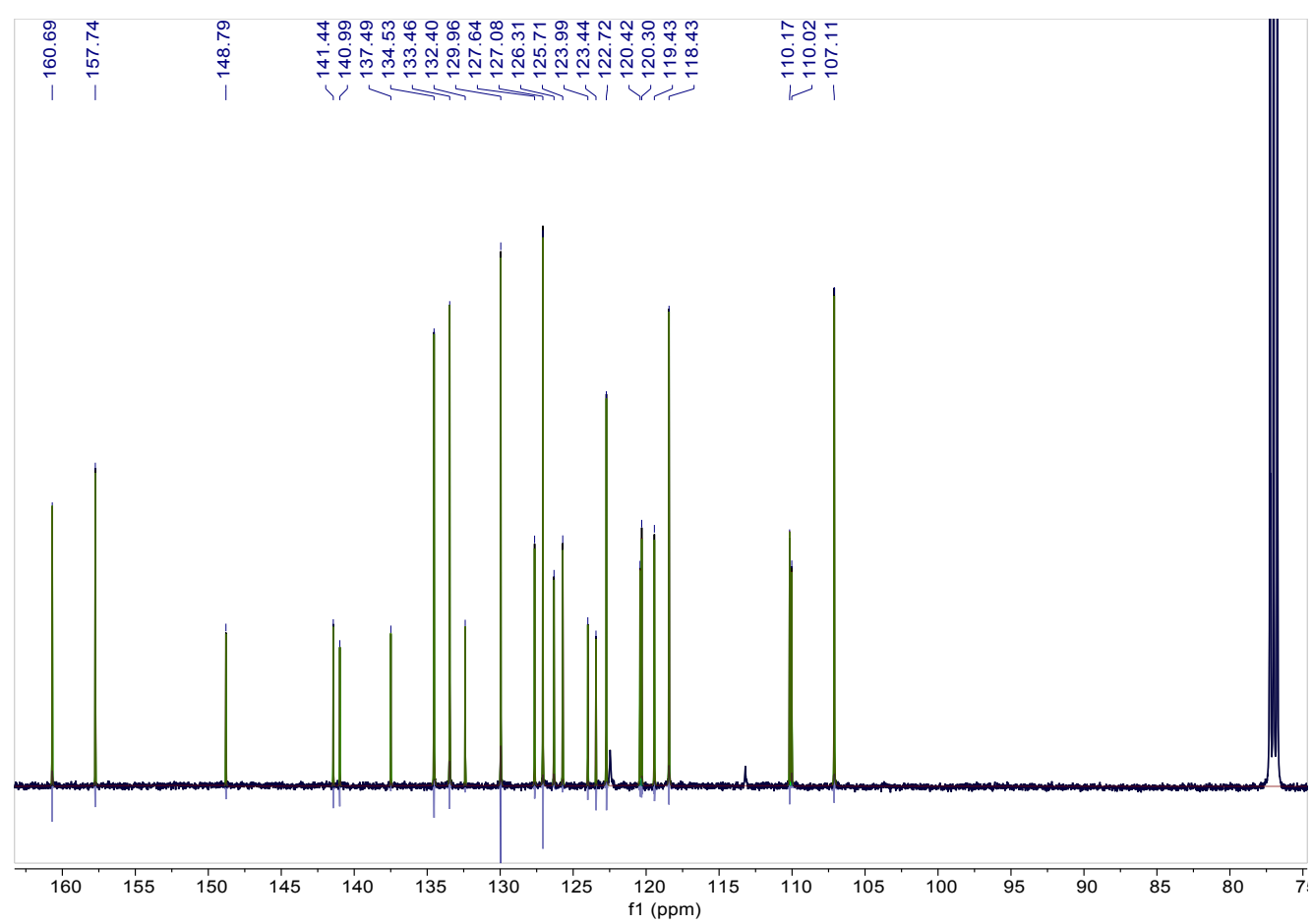

Figure S25. ${ }^{13} \mathrm{C}-\mathrm{NMR}$ spectrum of $\mathrm{BOCz} \mathrm{Ph}(126 \mathrm{MHz}$, chloroform- $d$ ). 
Table S1. Summary of the optical properties of the perovskite films with different thickness.

\begin{tabular}{cccccccccccc}
\hline $\begin{array}{c}\text { Thickness } \\
(\mathrm{nm})\end{array}$ & $\mathrm{A}_{1}$ & $\mathrm{~A}_{2}$ & $\mathrm{~A}_{3}$ & $\begin{array}{c}\mathrm{T}_{1} \\
(\mathrm{~ns})\end{array}$ & $\begin{array}{c}\mathrm{T}_{2} \\
(\mathrm{~ns})\end{array}$ & $\begin{array}{c}\mathrm{T}_{3} \\
(\mathrm{~ns})\end{array}$ & $\mathrm{X}^{2}$ & $\begin{array}{c}\mathrm{T}_{\text {ave }} \\
(\mathrm{ns})\end{array}$ & $\begin{array}{c}\text { PLQY } \\
(\%)\end{array}$ & $\begin{array}{c}\mathrm{k}_{\mathrm{r}} \\
\left(10^{6} \mathrm{~s}^{-1}\right)\end{array}$ & $\begin{array}{c}\mathrm{k}_{\mathrm{nr}} \\
\left(10^{6} \mathrm{~s}^{-1}\right)\end{array}$ \\
\hline 50 & 4342.6 & 599.9 & 29.3 & 4.25 & 12.9 & 105.6 & 1.17 & 17.3 & 60.1 & 34.7 & 16.7 \\
40 & 4531.3 & 771.8 & 31.7 & 4.25 & 13.2 & 97.4 & 1.17 & 15.9 & 51.0 & 32.1 & 30.8 \\
30 & 4079.1 & 927.1 & 23.1 & 3.28 & 14.3 & 92.5 & 1.17 & 15.0 & 32.8 & 21.9 & 44.8 \\
\hline
\end{tabular}

Table S2. Summary of the performance of devices R1, R2, R3, B1, B2, B3 and W6.

\begin{tabular}{ccccccc}
\hline Devices & $\begin{array}{c}\mathrm{V}_{\text {on }} \\
(\mathrm{V})\end{array}$ & $\begin{array}{c}\mathrm{L}_{\text {max }} \\
\left(\mathrm{cd} \mathrm{m}^{-2}\right)\end{array}$ & $\begin{array}{c}\mathrm{CE}_{\max } \\
\left(\mathrm{cd} \mathrm{A}^{-1}\right)\end{array}$ & $\begin{array}{c}\mathrm{EQE}_{\max } \\
(\%)\end{array}$ & $\begin{array}{c}\text { Peak } \\
(\mathrm{nm})\end{array}$ & $\begin{array}{c}\mathrm{CIE} \\
(\mathrm{x}, \mathrm{y})\end{array}$ \\
\hline $\mathrm{R} 1$ & 2.5 & 634 & 3.15 & 5.56 & 654 & $(0.699,0.301)$ \\
$\mathrm{R} 2$ & 2.5 & 559 & 2.25 & 3.96 & 652 & $(0.699,0.300)$ \\
$\mathrm{R} 3$ & 2.5 & 475 & 1.68 & 2.86 & 650 & $(0.697,0.302)$ \\
B1 & 2.9 & 7288 & 5.70 & 3.35 & 480 & $(0.149,0.189)$ \\
B2 & 3.0 & 7397 & 19.1 & 6.77 & 475,497 & $(0.157,0.340)$ \\
B3 & 2.7 & 1855 & 7.71 & 3.17 & 475,497 & $(0.165,0.339)$ \\
W6 & 2.5 & 461 & 2.18 & 3.49 & 652 & $(0.699,0.302)$ \\
\hline
\end{tabular}

Table S3. Summary of perovskite-based white electroluminescent devices.

\begin{tabular}{|c|c|c|c|c|c|c|c|}
\hline Year & Emitting layer & $\begin{array}{l}V_{\text {on }} \\
(V)\end{array}$ & $\begin{array}{l}\mathrm{EQE}_{\max } \\
\quad(\%)\end{array}$ & $\underset{\left(\operatorname{cd~m} \mathbf{m}^{-2}\right)}{\mathbf{L}_{\max }}$ & $\begin{array}{c}\mathbf{C C T} \\
(\mathbf{K})\end{array}$ & Device life & Ref. \\
\hline 2017 & $\begin{array}{c}\mathrm{HFSO}+ \\
\mathrm{CsPb}\left(\mathrm{Br}_{1.5} \mathrm{I}_{1.5}\right)\end{array}$ & 4.7 & & 1200 & & & 15 \\
\hline 2017 & $\begin{array}{l}\text { MEH-PPV + } \\
\mathrm{CsPb}\left(\mathrm{Br}_{\mathrm{x}} / \mathrm{l}_{3-\mathrm{x}}\right)\end{array}$ & 3.3 & & 105 & & & 16 \\
\hline 2018 & $\begin{array}{l}\mathrm{PA}_{2} \mathrm{CsPb}_{2} \mathrm{I}_{7} / \\
\mathrm{CsPb}(\mathrm{Br}, \mathrm{Cl})_{3}\end{array}$ & & 0.22 & & 6000 & & 17 \\
\hline 2019 & $\begin{array}{l}\mathrm{MAPb}(\mathrm{Br} / \mathrm{Br}, \mathrm{cl})_{3}+ \\
\text { compound }\end{array}$ & & $\begin{array}{c}0.01 \\
0.001\end{array}$ & & $\begin{array}{l}27.5 \\
-100\end{array}$ & & 18 \\
\hline 2019 & $\begin{array}{c}\mathrm{ZnCds} / \mathrm{ZnS} / \\
\mathrm{CsPb}\left(\mathrm{Br}_{1.65} / \mathrm{I}_{1.35}\right)\end{array}$ & 2.8 & 0.015 & 275 & 5153 & & 19 \\
\hline 2019 & $\begin{array}{c}\mathrm{CsPb}\left(\mathrm{Br}_{2.5} \mathrm{I}_{0.5}\right) / \mathrm{NPB} / \\
\mathrm{Cs} \mathrm{PbBr}_{3}\end{array}$ & & & 360 & & & 20 \\
\hline 2020 & CsPBA-2/ SPR-001 & & 1.3 & & $\begin{array}{l}5580- \\
8217\end{array}$ & $\begin{array}{c}\mathrm{L}_{0}=9.5 \mathrm{~cd} \mathrm{~m}^{-2} \\
\mathrm{~T}_{50}=135 \mathrm{~s}\end{array}$ & 21 \\
\hline 2020 & $\mathrm{CsPbCl}_{3}-\mathrm{Sm}^{3+}$ & & 1.2 & 938 & & @ $6 \mathrm{~V}$ & 22 \\
\hline
\end{tabular}




$$
\mathrm{T}_{50}=140 \mathrm{~s}
$$

\begin{tabular}{|c|c|c|c|c|c|c|c|}
\hline 2020 & $\begin{array}{c}\mathrm{MAPb}\left(\mathrm{Br}_{0.6} \mathrm{cl}_{0.4}\right)_{3} \\
\quad \text { Rhodamine } 6 \mathrm{G}\end{array}$ & & 0.003 & & $\begin{array}{l}5627 \\
2769\end{array}$ & & 23 \\
\hline 2020 & $\begin{array}{l}\mathrm{CsPb}\left(\mathrm{Br}_{1-\mathrm{x}} \mathrm{Cl}_{\mathrm{x}}\right)_{3} \\
\mathrm{CsPb}\left(\mathrm{Br}_{1-\mathrm{y}} \mathrm{I}_{\mathrm{y}}\right)_{3}\end{array}$ & & 0.008 & 38 & & & 24 \\
\hline 2020 & $\begin{array}{ll}\alpha & \mathrm{CsPbI}_{3} \\
\delta & \mathrm{CsPbI}_{3}\end{array}$ & 3.6 & 6.5 & 12200 & 6900 & $\begin{array}{l}\text { @ } 1 \mathrm{~mA} \mathrm{~cm}-2 \\
\mathrm{~T}_{50}=230 \mathrm{~min}^{-}\end{array}$ & 25 \\
\hline 2021 & $\begin{array}{c}\mathrm{Cs}_{3} \mathrm{Cu}_{2} \mathrm{I}_{5}, \mathrm{CsCu}_{2} \mathrm{I}_{3} \\
+ \text { Tween }\end{array}$ & 2.7 & 3.1 & 1570 & & & 26 \\
\hline- & $\begin{array}{l}\text { perovskite/ TAPC/ } \\
\text { Firpic/ BOCzPh }\end{array}$ & 3.0 & 7.35 & 764 & 2868 & $\begin{array}{c}\mathrm{L}_{0}=100 \mathrm{~cd} \mathrm{~m}^{-2} \\
\mathrm{~T}_{55}=638 \mathrm{~s}\end{array}$ & $\begin{array}{l}\text { This } \\
\text { work }\end{array}$ \\
\hline
\end{tabular}

\section{References:}

(1) Li, C.; Wang, N.; Guerrero, A.; Zhong, Y.; Long, H.; Miao, Y.; Bisquert, J.; Wang, J.; Huettner, S. Understanding the Improvement in the Stability of a Self-Assembled MultipleQuantum Well Perovskite Light-Emitting Diode. J. Phys. Chem. Lett. 2019, 10 (21), 68576864.

(2) Wang, N.; Cheng, L.; Ge, R.; Zhang, S.; Miao, Y.; Zou, W.; Yi, C.; Sun, Y.; Cao, Y.; Yang, R.; Wei, Y.; Guo, Q.; Ke, Y.; Yu, M.; Jin, Y.; Liu, Y.; Ding, Q.; Di, D.; Yang, L.; Xing, G.; Tian, H.; Jin, C.; Gao, F.; Friend, R. H.; Wang, J.; Huang, W. Perovskite LightEmitting Diodes Based on Solution Processed Self-Organized Multiple Quantum Wells. Nat. Photon. 2016, 10, 699-704.

(3) Li, Z.; Chen, Z.; Yang, Y.; Xue, Q.; Yip, H.-L.; Cao, Y. Modulation of Recombination Zone Position for Quasi-Two-Dimensional Blue Perovskite Light-Emitting Diodes with Efficiency Exceeding 5\%. Nat. Commun. 2019, 10 (1),1027-1036.

(4) Bischak, C. G.; Hetherington, C. L.; Wu, H.; Aloni, S.; Ogletree, D. F.; Limmer, D. T.; Ginsberg, N. S. Origin of Reversible Photoinduced Phase Separation in Hybrid Perovskites Nano Lett. 2017, 17 (2), 1028-1033.

(5) Vashishtha, P.; Halpert, J. E. Field-Driven Ion Migration and Color Instability in RedEmitting Mixed Halide Perovskite Nanocrystal Light-Emitting Diodes. Chem. Mater. 2017, 29 (14), 5965-5973.

(6) Yuan, F.; Zheng, X.; Johnston, A.; Wang, Y.; Zhou, C.; Dong, Y.; Chen, B.; Chen, H.; Fan, J.; Sharma, G.; Li, P.; Gao, Y.; Voznyy, O.; Kung, H.; Lu, Z.; Bakr, O.; Sargent, E. H. Color-Pure Red Light-Emitting Diodes Based on Two-Dimensional Lead-Free Perovskites. Sci. Adv. 2020, 6 (42), eabb0253. 
(7) Ahn, D. H.; Kim, S. W.; Lee, H.; Ko, I. J.; Karthik, D.; Lee, J. Y.; Kwon, J. H. Highly Efficient Blue Thermally Activated Delayed Fluorescence Emitters Based on Symmetrical and Rigid Oxygen-Bridged Boron Acceptors. Nat. Photon. 2019, 13, 540-546.

(8) Karthik, D.; Jung, Y. H.; Lee, H.; Hwang, S.; Seo, B. M.; Kim, J. Y.; Han, C. W.; Kwon, J. H. Acceptor-Donor-Acceptor-Type Orange-Red Thermally Activated Delayed Fluorescence Materials Realizing External Quantum Efficiency Over 30\% with Low Efficiency Roll-Off. Adv. Mater. 2021, 33, 2007724.

(9) Wang, Q.; Tian Q.-S.; Zhang Y.-L.; Tang X.; Liao L.-S. High-Efficiency Organic LightEmitting Diodes with Exciplex Hosts. J. Mater. Chem. C 2019, 7, 11329-11360.

(10) Zhang, M.; Zheng, C.-J.; Lin, H.; Tao, S.-L. Thermally Activated Delayed Fluorescence Exciplex Emitters for High-Performance Organic Light-Emitting Diodes. Mater. Horiz. 2021, $8(4), 1297-1303$.

(11) Chen, Z.; Li, Z.; Chen, Z.; Xia, R.; Zou, G.; Chu, L.; Su, S.-J.; Peng, J.; Yip, H.-L.; Cao, Y. Utilization of Trapped Optical Modes for White Perovskite Light-Emitting Diodes with Efficiency over 12\%. Joule 2021, 5 (2), 456-466.

(12) Liang, A.; Wang, K.; Gao, Y.; Finkenauer, B. P.; Zhu, C.; Jin, L.; Huang, L.; Dou, L. Highly Efficient Halide Perovskite Light-Emitting Diodes via Molecular Passivation. Angew. Chem. Int. Ed. 2021, 60 (15), 8337-8343.

(13) Liu, Y.; Ono, L. K.; Tong, G.; Zhang, H.; Qi, Y. Two-Dimensional Dion-Jacobson Structure Perovskites for Efficient Sky-Blue Light-Emitting Diodes. ACS Energy Lett. 2021, 6 (3), 908-914.

(14) Xiao Z.; Kerner R. A.; Zhao L.; Tran N. L.; Lee K.; Koh T.-W.; Scholes G. D.; Rand B. P. Efficient Perovskite Light-Emitting Diodes Featuring Nanometre-Sized Crystallites. Nat. Photon. 2017, 11, 108-115.

(15) Huang, C.-Y.; Huang, S.-J.; Liu, M.-H. M. Hybridization of $\mathrm{CsPbBr}_{1.5} \mathrm{I}_{1.5}$ Perovskite Quantum Dots with 9,9-dihexylfluorene Co-Oligomer for White Electroluminescence. Org. Electron. 2017, 44, 6-10.

(16) Sun, C.; Zhang, Y.; Ruan, C.; Yin, C. Y.; Wang, X. Y.; Wang, Y. D.; Yu, W. W. Efficient and Stable White LEDs with Silica-Coated Inorganic Perovskite Quantum Dots. Adv. Mater. 2016, 28 (45), 10088-10094.

(17) Mao, J.; Lin, H.; Ye, F.; Qin, M.; Burkhartsmeyer, J. M.; Zhang, H.; Lu, X.; Wong, K. S.; Choy, W. C. H. All-Perovskite Emission Architecture for White Light-Emitting Diodes. ACS Nano 2018, 12 (10), 10486-10492.

(18) Chang, C.-Y.; Solodukhin, A. N.; Liao, S.-Y.; Mahesh, K. P. O.; Hsu, C.-L.; 
Ponomarenko, S. A.; Luponosov, Y. N.; Chao, Y.-C. Perovskite White Light-Emitting Diodes Based on a Molecular Blend Perovskite Emissive Layer. J. Mater. Chem. C 2019, 7 (28), 8634-8642.

(19) Wang, C.; Xue, D.; Shen, X.; Wu, H.; Zhang, Y.; Cui, H.; Yu, W. W. White LightEmitting Devices Based on $\mathrm{ZnCdS} / \mathrm{ZnS}$ and Perovskite Nanocrystal Heterojunction. Nanotechnol. 2019, 30 (46), 465201-465209.

(20) Chen, S. M.; Chen, C.; Bao, C.; Mujahid, M.; Li, Y.; Chen, P.; Duan, Y. White LightEmitting Devices Based on Inorganic Perovskite and Organic Materials. Molecules 2019, 24, 800.

(21) Jamaludin, N. F.; Yantara, N.; Giovanni, D.; Febriansyah, B.; Tay, Y. B.; Salim, T.; Sum, T. C.; Mhaisalkar, S.; Mathews, N. White Electroluminescence from PerovskiteOrganic Heterojunction. ACS Energy Lett. 2020, 5 (8), 2690-2697.

(22) Sun, R.; Lu, P.; Zhou, D.; Xu, W.; Ding, N.; Shao, H.; Zhang, Y.; Li, D.; Wang, N.; Zhuang, X.; Dong, B.; Bai, X.; Song, H. Samarium-Doped Metal Halide Perovskite Nanocrystals for Single-Component Electroluminescent White Light-Emitting Diodes. ACS Energy Lett. 2020, 5 (7), 2131-2139.

(23) Chang, C.-Y.; Hong, W.-L.; Lo, P.-H.; Wen, T.-H.; Horng, S.-F.; Hsu, C.-L.; Chao, Y.C. Perovskite White Light-Emitting Diodes with a Perovskite Emissive Layer Blended with Rhodamine 6G. J. Mater. Chem. C 2020, 8 (37), 12951-12958.

(24) Yu, H.; Wang, H.; Pozina, G.; Yin, C.; Liu, X.-K.; Gao, F. Single-Emissive-Layer AllPerovskite White Light-Emitting Diodes Employing Segregated Mixed Halide Perovskite Crystals. Chem. Sci. 2020, 11 (41), 11338-11343.

(25) Chen, H.; Zhu, L.; Xue, C.; Liu, P.; Du, X.; Wen, K.; Zhang, H.; Xu, L.; Xiang, C.; Lin, C.; Qin, M.; Zhang, J.; Jiang, T.; Yi, C.; Cheng, L.; Zhang, C.; Yang, P.; Niu, M.; Xu, W.; Lai, J.; Cao, Y.; Chang, J.; Tian, H.; Jin, Y.; Lu, X.; Jiang, L.; Wang, N.; Huang, W.; Wang, J. Efficient and Bright Warm-White Electroluminescence from Lead-Free Metal Halides. Nat. Commun. 2021, 12 (1), 1421-1427.

(26) Chen, J.; Wang, J.; Xu, X.; Li, J.; Song, J.; Lan, S.; Liu, S.; Cai, B.; Han, B.; Precht, J. T.; Ginger, D.; Zeng, H. Efficient and Bright White Light-Emitting Diodes Based on SingleLayer Heterophase Halide Perovskites. Nat. Photon. 2021, 15, 238-244. 